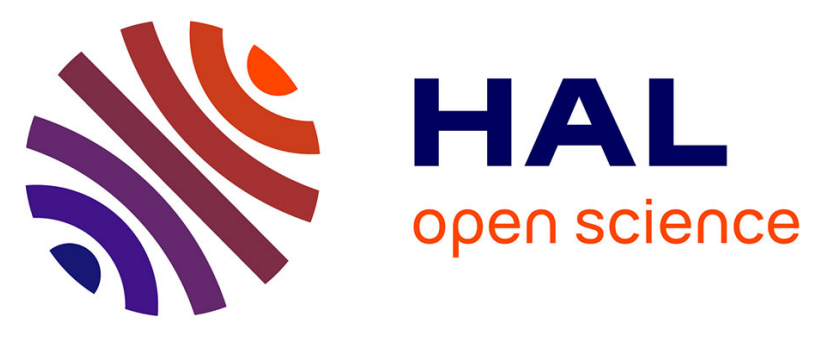

\title{
Coupling of pressure-driven membrane technologies for concentrating, purifying and fractionizing betacyanins in cactus pear (Opuntia dillenii Haw.) juice
}

\author{
Abdoulaye Tamba, Adrien Servent, Christian Mertz, Mady Cissé, Manuel \\ Dornier
}

\section{To cite this version:}

Abdoulaye Tamba, Adrien Servent, Christian Mertz, Mady Cissé, Manuel Dornier. Coupling of pressure-driven membrane technologies for concentrating, purifying and fractionizing betacyanins in cactus pear (Opuntia dillenii Haw.) juice. Innovative Food Science \& Emerging Technologies / Innovative Food Science and Emerging Technologies , 2019, 52, pp.244-255. 10.1016/j.ifset.2018.12.008 . hal-02024062

\section{HAL Id: hal-02024062 \\ https://institut-agro-montpellier.hal.science/hal-02024062}

Submitted on 21 Oct 2021

HAL is a multi-disciplinary open access archive for the deposit and dissemination of scientific research documents, whether they are published or not. The documents may come from teaching and research institutions in France or abroad, or from public or private research centers.
L'archive ouverte pluridisciplinaire HAL, est destinée au dépôt et à la diffusion de documents scientifiques de niveau recherche, publiés ou non, émanant des établissements d'enseignement et de recherche français ou étrangers, des laboratoires publics ou privés.

\section{(ㄷ)(1) $\$$}

Distributed under a Creative Commons Attribution - NonCommerciall 4.0 International 
1 Coupling of pressure-driven membrane technologies for concentrating, purifying and

2 fractionizing betacyanins in cactus pear (Opuntia dillenii Haw.) juice

3

TAMBA Abdoulaye ${ }^{\mathrm{a}}$, SERVENT Adrien ${ }^{\mathrm{b}, \mathrm{c}}$, MERTZ Christian $^{\mathrm{b}, \mathrm{c}}$, CISSE Mady $^{\mathrm{a}}$, DORNIER Manuel $^{\text {b* }}$

a Laboratoire de Microbiologie Appliquée et de Génie Industriel, Ecole Supérieure Polytechnique, Université Cheikh Anta Diop, BP 5005 Dakar-Fann, Dakar, Sénégal

b QualiSud, Univ Montpellier, CIRAD, Montpellier SupAgro, Univ Avignon, Univ Réunion, Montpellier, France

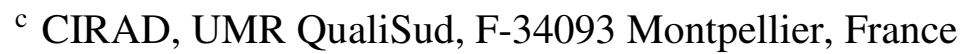

*Corresponding author: <manuel.dornier@supagro.fr>, tel.: +33/467614432

\section{Abstract}

An integrated process coupling crossflow micro and ultra or nanofiltration was applied to separate the betacyanins in cactus pear juice $\left(30^{\circ} \mathrm{C}\right)$. Four microfiltration ceramic membranes (0.1-0.2 $\mu \mathrm{m}, 1.8-3.3 \mathrm{bar})$ and $4 \mathrm{ultra} /$ nanofiltration organic membranes (0.2-4.0 kDa, 5-30 bar) were tested. Microfiltration was a first step to remove insoluble solids with low retention of soluble solids. By coupling with enzymatic liquefaction, permeate flux Jp was increased by 2 and the retention of betacyanins was limited. Ultra/nanofiltration was then used for solute separation. Retentions of solutes could be modulated by varying membrane/pressure combinations that favor rather the concentration of all the solutes or rather the purification of the betacyanins with respect to the total dry matter. Retention of individual betacyanins could be a little different which also made possible fractionation. Simulations using simple models allowed to evaluate the interest of the process for concentrating, purifying and fractionating betacyanins with a possible diafiltration step.

Keywords: Opuntia dillenii ; betacyanins ; concentration ; purification ; fractionation ; microfiltration ; ultrafiltration ; nanofiltration 
33 Betacyanins are natural colorants that can be obtained from cactus pear juice, a crop of increasing interest for its agricultural potential in sahelian regions. The aim of this study was to evaluate a new integrated process based on membrane separation allowing to concentrate or separate betacyanins from other solutes at low temperature and with a limited environmental impact. This process associates a first step to clarify the cactus pear juice by microfiltration after enzymatic liquefaction and a second step to concentrate or purify betacyanins by ultra or nanofiltration. By choosing different membrane / transmembrane pressure combinations in the $2^{\text {nd }}$ step, solute retentions could be modulated in order to favour rather the concentration of all solutes or rather the separation of betacyanins from total soluble solids or even rather the fractionation of betacyanins themselves.

\section{Highlights}

- Coupling micro and ultra/nanofiltration to separate betacyanins in cactus pear juice

- Microfiltration with enzymatic liquefaction for clarifying with low solute retention

- Ultra/nanofiltration for concentrating or purifying betacyanins

- Separation pattern modulated thanks to different membrane/pressure combinations 
49 Notation

50

$51 \quad \mathrm{C}_{\mathrm{i}} \quad$ concentration of compound $\mathrm{i}\left(\mathrm{g} \mathrm{kg}^{-1}\right)$

$52 \mathrm{CF}_{\mathrm{i}}$ concentration factor of compound $\mathrm{i}$

53 DV diavolume (or dilution ratio)

$54 \mathrm{Jp} \quad$ permeate flux $\left(\mathrm{kg} \mathrm{h}^{-1} \mathrm{~m}^{-2}\right)$

55 MRR mass reduction ratio

$56 \quad$ MWCO molecular weight cut-off

$57 \quad R_{i} \quad$ retention of compound $i$

$58 \quad \mathrm{SF}_{\mathrm{i} / \mathrm{j}} \quad$ separation factor of compound $\mathrm{i}$ from compound $\mathrm{j}$

59 TDM total dry matter $\left(\mathrm{g} \mathrm{kg}^{-1}\right)$

60 TMP transmembrane pressure (bar)

61

$62 \beta \mathrm{c} \quad$ total betacyanins

$63 \beta \mathrm{n} \quad$ betanin

$64 \mathrm{i} \beta \mathrm{n} \quad$ isobetanin

$65 \mathrm{n} \beta \mathrm{n} \quad$ neobetanin

66 


\section{Introduction}

Natural products with beneficial effects on human health, used as colorants and antioxidants, have attracted a lot of attention. Recently, there is a large amount of natural colorants, extracted from various natural raw materials, rich in compounds such as anthocyanins, carotenoids, chlorophylls and betalains. Betalains are water-soluble vacuolar chromoalkaloids found in plants of the order Caryophyllales as well as in some Basidiomycetes (Azeredo, 2009; Herbach, Stintzing, \& Carle, 2006; Stintzing \& Carle, 2004).

Structurally, betacyanins are characterized by a cyclo-Dopa structure with additional substitutions through varying glycosylation and acylation patterns at $\mathrm{C}_{5}$ or $\mathrm{C}_{6}$ while betaxanthins are condensation products of betalamic acid and various amino compounds. Betacyanins can be classified according to their chemical structures into 4 types: betanin-type, amaranthine-type, gomphrenin-type and bougainvillea-type (Cai, Sun, \& Corke, 2005; Stintzing, et al., 2004). The sources of betanin used for food-colouring contain, amongst other substances, a mixture of betanin and its epimer isobetanin (Gonçalves, et al., 2012).

Betalains have a number of health properties. Infusions of betalains from the bracts of Bougainvillaea mixed with honey, for example, are used to treat coughs in some regions of Mexico (Heinrich, 2003). Certain anticancer, antiviral, antibacterial and antioxidant activities has been attributed to betalains (Cejudo-Bastante, Chaalal, Louaileche, Parrado, \& Heredia, 2014; Hilou, Nacoulma, \& Guiguemde, 2006). They are widely used as natural red food colorant as well as potential antioxidant (Chauhan et al. 2012). Betalains are less commonly used than anthocyanins and carotenoids, although these water-soluble pigments, stable between pH 3 and 7, are well suited for coloring low-acid food (Neelwarne, 2012).

The main source of betalains, especially betanins, is the beet root (Beta vulgaris), classified as additive E-162 (EU) and 73.40 (FDA, USA), mainly used to color foods, such as dairy products, confectionery, ice cream, desserts, drinks and sausages (Obón, Castellar, Alacid, \& Fernández-López, 2009). Nevertheless, the preparations obtained from this root have undesirable earthy flavors (R. Castellar, Obón, Alacid, \& Fernández-López, 2003) and the presence of high concentrations of labile betaxanthins limits their use as a food coloring (Calvo \& Salvador, 2000; Nemzer, et al., 2011).

The purple cactus pear is an interesting alternative as a source of betacyanins for the production of food colouring (R. Castellar, et al., 2003; Delgado-Vargas, Jiménez, \& Paredes- 
López, 2000; Saénz, Tapia, Chávez, \& Robert, 2009). Recently, the study of cactus pear has become increasingly important because of its high content of betalains and other phenolic compounds (Cejudo-Bastante, et al., 2014). The cactus pear fruits are characterized by various colors due to the combination of two betalain pigments, purple betanin and yellow-orange indicaxantin (Fernandez-Lopez \& Almela, 2001). Cactus pear (Opuntia sp) is classified as a specy with high hydric stress tolerance, its cultivation is adequate in arid and semi-arid regions and for poor soils. Research has also indicated that the cactus pear has antiinflammatory, diuretic, antispasmodic activity (Ballero, Poli, Sacchetti, \& Loi, 2001; Loi, Poli, Sacchetti, Selenu, \& Ballero, 2004; Palmese, Manganelli, \& Tomei, 2001). Cactus pear fruit is a source of nutrients and vitamins (Sawaya, Khatchadourian, Safi, \& Al-Muhammad, 1983; Teles, Stull, Brown, \& Whiting, 1984).

Numerous studies have revealed the strong potential of membrane processes for the concentration and separation of thermosensitive bioactive compounds in fruit juices (Bhattacharjee, Saxena, \& Dutta, 2017). Among the various studies available in the literature, the separation of low molecular weight solutes using a low molecular weight cut-off ultrafiltration or a high MWCO nanofiltration is gaining increasing interest (Acosta, Vaillant, Pérez, \& Dornier, 2014; Conidi, Cassano, Caiazzo, \& Drioli, 2017; Nath, Dave, \& Patel, 2018). Indeed, even if this process requires pretreatment to avoid rapid fouling of the membrane, it could be used to achieve separations at low temperature, i.e. without damaging the potential of raw material, and with a fairly low environmental impact.

In recent years, some studies have focused on separation of betalains by membrane technologies. For example, (Vergara, Cancino-Madariaga, Ramírez-Salvo, Sáenz, Robert, \& Lutz, 2015) clarified a purple cactus pear juice by microfiltration. They obtained very clear permeates, free of turbidity, $70 \%$ of betalains retention and also containing polyphenols and high antioxidant activity. Ultrafiltration process has also been used to clarify yellow and red cactus pear pulp (Alfredo Cassano, Conidi, \& Drioli, 2010). Mereddy, Chan, Fanning, Nirmal, \& Sultanbawa (2017) increased the total betalain content in red beetroot extract up to $46 \%$ of the total soluble solids in the concentrated juice after three diafiltrations. In this context, this study aimed to evaluate a new integrated membrane-based process to concentrate betacyanins, but also to purify or fractionate them. The method selected consisted of a first clarification step by microfiltration and a second step for solute separation by ultra or nanofiltration. It was evaluated by applying these pressure-driven technologies to the treatment of a cactus pear juice of Opuntia dillenii (Ker Gawl.) Haw. from Senegal. 


\section{Materials and methods}

134

\subsection{Cactus pear juice preparation}

The juice was obtained from purple cactus pears (Opuntia dillenii Haw.) harvested from a plantation in Saint-Louis, Senegal. The fruits $(45.5 \mathrm{~kg})$ were manually washed with water and peeled. The peeled fruit $(22.2 \mathrm{~kg})$ was then refined using a horizontal pulper Auriol PH3 (Marmande, France) with $0.5 \mathrm{~mm}$ mesh at room temperature in order to separate the seeds from the juice. The $18.2 \mathrm{~kg}$ of refined juice obtained were frozen at $-18^{\circ} \mathrm{C}$ until use. All the juice used in the experiments was produced at the same time.

\subsection{Enzymatic liquefaction and clarification by microfiltration}

Part of the juice was enzymatically pretreated using $300 \mathrm{mg} \cdot \mathrm{kg}^{-1}$ of Ultrazym AFP-L (Novozymes, Bagsvaerd, Denmark). The mixture was stirred for $30 \mathrm{~min}$ at $30^{\circ} \mathrm{C}$ without any $\mathrm{pH}$ adjustment.

Microfiltration experiments were performed using a laboratory pilot already described by (Polidori, Dhuique-Mayer, \& Dornier, 2018). The pilot consisted of a 3 L feed tank, 4 tubular ceramic membranes with an effective filtration area of $55 \mathrm{~cm}^{2}$, and a tubular heat exchanger to keep the juice temperature at $30 \pm 1^{\circ} \mathrm{C}$. The details of the 4 microfiltration membranes used throughout the experiment have been listed in Table 1.

For the comparison of operating conditions (membrane and transmembrane pressure TMP), the feed composition was kept constant by recycling the entire permeate in the feed tank as usual (MRR mass reduction ratio, defined as the ratio between the total mass of the feed and the mass of the retentate in the circulation loop, kept close to 1). The best operating conditions were selected on the basis of the highest permeate flux (Jp) and the lowest retention of betacyanins.

The juice was then clarified according to a classical batch concentration procedure. In that case, the permeate was separately collected keeping the mass of the retentate constant in the circulation loop with the addition of raw juice to the feed tank. Four similar tubular membranes were connected to obtain a total effective surface of $220 \mathrm{~cm}^{2}$. The system was implemented to clarify the juice up to a MRR mass reduction ratio of 5. This clarified juice was subjected to a second separation step performed by ultra or nanofiltration. 
and standard deviation evaluated with 3 or 4 measurements.

\subsection{Separation by nano/ultrafiltration}

\subsubsection{Equipment and experimental procedure}

Nano/ultrafiltration experiments were carried out using the pilot unit already described by (Cissé, Vaillant, Pallet, \& Dornier, 2011), which incorporated a Sepa CF II Membrane Cell System (GE Osmonics, Minnetonka, MN, USA) with an effective membrane surface of 155 $\mathrm{cm}^{2}$. The temperature was maintained at $30 \pm 0.5^{\circ} \mathrm{C}$ using a Julabo F12-ED cryostat (Seelbach, Germany) which fed the double jacket of the feed tank. The permeate mass flux was determined by weighing the amount of permeate extracted Vs. time with a Precisa XL 1200C electronic scale (Dietikon, Switzerland). For each trial, $2.5 \mathrm{~kg}$ of extract was used. Extracted permeate weight, transmembrane pressure and temperature were recorded every 2 min. Four flat-sheet membranes characteristics were used in this experiment and their respective water permeability values are reported in Table 1.

Before filtration, membranes were pre-conditioned during $60 \mathrm{~min}$, using deionized water (conductivity $<5 \mu \mathrm{S} . \mathrm{cm}^{-1}$ ) at $30^{\circ} \mathrm{C}$, at 20 bar of transmembrane pressure and $0.3 \mathrm{~m} . \mathrm{s}^{-1}$ of crossflow velocity. Water flux from the last $10 \mathrm{~min}$ of preconditioning was used to calculate membrane permeability. Experiments were performed immediately after preconditioning. The permeate and retentate fractions were recycled to the feed tank to maintain a constant feed concentration $(\mathrm{MRR} \approx 1)$.

The transmembrane pressures tested for each membrane were 5, 10, 15, 20, 25 and 30 bar, with each pressure level being maintained for 50 min with the except of the Nadir $4 \mathrm{kDa}$ membrane where pressures were limited to 15 bar. All permeate flux values were recorded during the last $10 \mathrm{~min}$ for each pressure set point and $30 \mathrm{~mL}$ of permeate samples were collected. Samples, feed juice and permeates, were immediately frozen and kept at $-18{ }^{\circ} \mathrm{C}$ until analysis.

Membrane performance was evaluated by its permeate flux (Jp) and its selectivity towards total betacyanins $\beta c$, betanin $\beta n$, isobetanin i $\beta n$ and neobetanin $n \beta n$. The retention of the compound i $\mathrm{R}_{\mathrm{i}}$ was calculated according to Eq. 1. where $\mathrm{C}_{\mathrm{pi}}$ and $\mathrm{C}_{\mathrm{fi}}$ the concentrations in $\mathrm{g} \cdot \mathrm{kg}^{-}$ ${ }^{1}$ of the compound $\mathrm{i}$ in the permeate and in the feed, respectively. 


$$
\mathrm{R}_{i}=1-\frac{\mathrm{C}_{\mathrm{pi}}}{\mathrm{C}_{\mathrm{fi}}}
$$

Eq. 1

\subsubsection{Modeling betacyanins concentration and separation}

198

199

200

201

202

203

204

From mass balance, assuming that the retentions are constant and the system behaves like an ideal stirred reactor, concentration factor of an element $\mathrm{i}$ in the retentate $\mathrm{CF}_{\mathrm{i}}$ after nanofiltration up to a mass reduction ratio MRR and diavolume DV (defined as the ratio between the volume of water added during the diafiltration phase and the volume of retentate), could be evaluated using Eq. 2 with $C_{i}$ the concentration of the compound $i$ in the retentate and $R_{i}$ the retention of $i$ (Acosta, et al., 2014; Polidori, et al., 2018; L. Wang, Yang, Xing, \& Xu, 2008; X.-L. Wang, Zhang, \& Ouyang, 2002). In order to evaluate the ability of the process to separate two solutes $\mathrm{i}$ and $\mathrm{j}$, a separation factor $\mathrm{SF}_{\mathrm{i} / \mathrm{j}}$ was also defined according to Eq. 3. In the case where the compound $\mathrm{i}$ was the most retained, the higher the $\mathrm{SF}_{\mathrm{i} / \mathrm{j}}$ the more efficient the separation between $\mathrm{i}$ and $\mathrm{j}$. Considering betacyanins for $\mathrm{i}$ and total dry matter TDM for $\mathrm{j}$, this separation factor corresponds to a purification factor. Considering $\mathrm{i}$ and $\mathrm{j}$ two different betacyanins, it can be defined as a fractionation factor.

$$
\begin{gathered}
C F_{i}=\frac{C_{i}^{\text {final }}}{C_{i}^{\text {initial }}}=M R R^{R_{i}} e^{D V\left(R_{i}-1\right)} \\
S F_{i / j}=\frac{C F_{i}}{C F_{j}}=\exp \left[\left(R_{i}-R_{j}\right)(\ln M R R+D V)\right]
\end{gathered}
$$

\subsection{Analysis}

\subsubsection{Physicochemical characterization}

Total soluble solids (TSS) were measured using a refractometer Atago PAL-3 (Tokyo, Japan). The total dry matter (TDM) was measured in a vacuum oven at 30 mbar and $70^{\circ} \mathrm{C}$ according to $(\mathrm{AOAC}, 1990)$ procedure.

Conductivity $\left(\mathrm{mS.cm}^{-1}\right)$ and $\mathrm{pH}$ were measured at room temperature using a conductimeter WTW LF 197 (Weilheim, Germany) and a Schott Titroline apparatus (St. Gallen, 
Switzerland). Turbidity measurements were performed with a turbiditymeter Hanna LP 2000 (Rhode Island, USA).

The colour was measured using the $\mathrm{L}^{*}, \mathrm{a}^{*}$, and $\mathrm{b}^{*}$ coordinates of CIE Lab with a chromameter Minolta CR-410 (Tokyo, Japan). The index L* is related to the luminosity, varying between white and black; the color coordinates varying between greenish and reddish colours $\left(\mathrm{a}^{*}\right)$ and bluish and yellowish colours $\left(\mathrm{b}^{*}\right)$ (Sant'Anna, Gurak, Marczak, \& Tessaro, 2013).

Glucose, fructose and citric acid contents were determined by HPLC using a UPLC -1290 system Infinity II (Agilent, Santa-Clara, USA) equipped with RI and UV detectors. A C18 column (SHODEX SH1011, 300x8 mm; Tokyo, Japan) with a mobile phase of $\mathrm{H}_{3} \mathrm{PO}_{4}(0.1 \%)$ in water was used, with isocratic elution program at a flow rate of $0.7 \mathrm{~mL} \cdot \mathrm{min}^{-1}$ and $40^{\circ} \mathrm{C}$. Injection volume was $10 \mu \mathrm{L}$ and spectrophotometric detection was set at 210 and $245 \mathrm{~nm}$.

\subsubsection{Betalain analysis}

\subsubsection{Spectrophotometry analysis}

The total betacyanins were measured according to (A Cassano, Conidi, Timpone, D'avella, \& Drioli, 2007), in which juice samples were analysed using spectrophotometer Specord 600 (analytik Jena, Jena, Germany) at $535 \mathrm{~nm}$. Betacyanin contents $\left(\beta \mathrm{c}, \mathrm{mg} \mathrm{kg}^{-1}\right)$ were calculated according to the Beer-Lambert law using $60000 \mathrm{~L} \mathrm{~mol}^{-1} . \mathrm{cm}^{-1}$ as molar extinction coefficient and after diluting until absorbance between 0.2 and 0.8 .

\subsubsection{HPLC analysis}

HPLC separation and identification of betalains were performed with the same Agilent chromatographic system previously described for sugars and organic acid analysis. The samples were filtered through a $0.45 \mu \mathrm{m}$ nylon filter. All analyses were conducted in triplicate. Betalains identification was carried out using $1 \%$ formic acid in water (v/v, eluent A) and acetonitrile (eluent B). Betalains were separated in a Kinetex XB-C18 column $(150 \times$ $4.6 \mathrm{~mm}, 2.6 \mu \mathrm{m}$ particle size, Phenomenex, California, USA) maintained at $30^{\circ} \mathrm{C}$, at a flow rate of $1 \mathrm{~mL} \mathrm{~min}^{-1}$. The injection volume for all extracts was $10 \mu \mathrm{L}$. Betalain compounds were separated starting with $95 \% \mathrm{~A}$, followed by a linear gradient from 5 to $10 \% \mathrm{~B}$ in $5 \mathrm{~min}$, then a linear gradient from 10 to $20 \% \mathrm{~B}$ in $5 \mathrm{~min}$, and from 20 to $5 \% \mathrm{~B}$ in $2 \mathrm{~min}$. To re-establish 
the initial conditions, this condition was maintained (5\% B and 95\% A) during 3 min. Betacyanins and betaxanthins were monitored at 535 and $484 \mathrm{~nm}$, respectively. The identification of each chromatographic peak was tentatively assigned by their visible spectral characteristics in comparison with standard (betanin and isobetanin only) and retention times.

\subsubsection{LC-MS and NMR analysis}

LC-MS analysis were performed on an Acquity H-Class UPLC system (Waters Corp., Milford, MA), using a Kinetex C18 100 A $100 \times 2.1$ mm, $2.6 \mu \mathrm{m}$ column (Phenomenex) coupled with an Acquity PDA detector and with a mass spectrophotometer Synapt G2-S HDMS system (Waters Corp., Milford, MA) with electrospray ionization source operating in high resolution mode. The elution gradient was set as follow: from $95 \%$ formic acid $0.01 \%$ and $5 \%$ acetonitrile to $100 \%$ acetonitrile in $10 \mathrm{~min}$, flow rate was fixed at $0.4 \mathrm{ml} / \mathrm{min}$. The Synapt parameters were optimized as follow: the sample cone was set at $20 \mathrm{~V}$, the source and desolvation temperature were set at $140^{\circ} \mathrm{C}$ and $450^{\circ} \mathrm{C}$, respectively. Each sample were processed with MassLynx (V4.1) software.

Fractions for NMR were collected with a semi-preparative HPLC using Ultimate 3000 LC system (Thermo) equipped with an autosampler (WPS3000TFC) and then evaporated to dryness. NMR spectra were recorded at $298 \mathrm{~K}$ on a Bruker Avance III $600 \mathrm{MHz}$ NMR spectrometer, using TCI Cryoprobe Prodigy. Spectra were processed and visualized with Topspin 3.5 (Bruker Biospin) on a Linux station. Deuterium Oxide was purchased from Eurisotop, France.

\section{Results et discussion}

\subsection{Cactus pear juice composition}

The solutes mainly present in the cactus pear juice are glucose, fructose and citric acid (Table 2 , raw juice). Reducing sugars accounted for $70 \%$ of the total dry matter. The high proportion of citric acid in the dry matter, $19 \%$, explains the very acid character of the juice. The $\mathrm{pH}$ value was similar to that obtained by (M. Castellar, Obón, Alacid, \& Fernández-López, 2008; Medina, Rodríguez, \& Romero, 2007) who respectively obtained 3.30 and 3.34 but less than the $\mathrm{pH}$ values of $5.3-7.1$ reported for the cactus pear Opuntia ficus-indica, the most studied and cultivated Opuntia (A Cassano, et al., 2007; Moßhammer, Stintzing, \& Carle, 2006). 
The high turbidity of the raw juice showed a significant insoluble fraction. Nevertheless, the insoluble solids in suspension represented a small mass fraction of the total dry matter (TDM). Indeed, total soluble solids (TSS) were of the same order of magnitude as TDM.

The juice was also characterized by an intense red color due to the presence of betacyanins. The attained concentrations were similar to those presented by many other studies (M. Castellar, Obón, \& Fernández-López, 2006; R. Castellar, et al., 2003).

Following HPLC analysis, 3 majority peaks were observed at $484 \mathrm{~nm}$ (Fig. 1). Compounds 1 and 2 had a molecular weight identical toof 551.1511 and 551.1512 Da respectively that corresponded with the formula $\mathrm{C}_{25} \mathrm{H}_{26} \mathrm{~N}_{2} \mathrm{O}_{13}$. The MSMS confirmed the structure of the betanin. The two compositions presented identical HRMS and MSMS were highly likely to be, the isomers: betanin, isobetanin.

Compound 3 gave an exact mass of 549.1399 Da which corresponded to the molecular formula $\mathrm{C}_{25} \mathrm{H}_{24} \mathrm{~N}_{2} \mathrm{O}_{13}$. MSMS seemed to indicate that the double bond was in the nitrogen heterocycle of 6 carbon atoms with a characteristic fragment at $148 \mathrm{Da}$. The difference of -2 in mass with respect to the compounds 1 and 2 would result from oxidation, hence the presence of a double bond which is absent in betanin and neobetanin. In order to confirm this hypothesis, compound 3 was isolated by semi-preparatory HPLC to be analyzed by NMR. The HMBC experiment (1H-13C long distance) showed a correlation between quaternary $\mathrm{C}$ atom. Therefore, the position of the unsaturation was confirmed as being present on the cycle of 6 . The presence of the double bond at scale 6 of the cycle also explained the equivalence of the $2 \mathrm{H}$ "pyridine" that appeared at the same chemical shift $(7.90 \mathrm{ppm})$ for an integration of 2 which allowed identifying as the molecule as neobetanin.

Therefore, the three main betacyanins identified in the juice were betanin, isobetanin and neobetanin. Neobetanin $(14,15$-dehydro-betanin) is a natural constituent of beet (Beta vulgaris L.) (Alard, Wray, Grotjahn, Reznik, \& Strack, 1985; Kujala, Loponen, \& Pihlaja, 2001) or cactus pear (Opuntia sp.) (Alard, et al., 1985; Castellanos-Santiago \& Yahia, 2008; Wyler, 1986). It is formed by dehydrogenation of betanin (Wybraniec, Starzak, Skopińska, Nemzer, Pietrzkowski, \& Michałowski, 2013).

These three compounds have already been identified in the cactus pear (Chauhan, Sheth, Rathod, Suhagia, \& Maradia, 2013). 
In order to study the impact of enzymatic hydrolysis on juice and microfiltration, a proportion of the juice was treated with Ultrazym. The results showed that enzymatic treatment has no significant impact on the physiochemical characteristics of the juice (Table 2) even though, enzymatic treatment generally achieves a reduction of turbidity and an increase of TSS mainly due to the hydrolysis of polysaccharides and the release of soluble compounds (F. Vaillant, Millan, Jariel, Dornier, Decloux, \& Reynes, 1999; Fabrice Vaillant, Pérez, Acosta, \& Dornier, 2008).

\subsection{Membrane and TMP selection for clarification}

\subsubsection{Interest of the enzymatic liquefaction}

By filtering the raw juice without enzymatic liquefaction, the permeate flux was close to $40 \mathrm{~L}$ $\mathrm{h}^{-1} \mathrm{~m}^{-2}$ whatever the operating conditions (Fig. 2). In this case, the fluxes were constant during filtration that attested membrane fouling reached a steady state very early. On the contrary, flux behavoiur was completely modified by the enzymatic pretreatment. First, the flux was significantly improved. Second they were much less stable, with a 35\% drop after the first hour of filtration, which indicated that fouling required more time for setting up. These evolutions did not depend on the membrane nor the applied pressure. These results corroborate those of numerous studies that showed that enzymatic treatment very often improves membrane performance during fruit juice clarification (Bahçeci, 2012; Gökmen \& Çetinkaya, 2007; Ushikubo, Watanabe, \& Viotto, 2007; Watanabe, Ushikubo, \& Viotto, 2006). Indeed, the enzymatic liquefaction decreases the viscosity of the juice but also modifies the fouling power of the suspension. It helps to solubilize part of the insoluble fraction and modifies the colloidal fraction known to be often involved in fouling (Dahdouh, Delalonde, Ricci, Servent, Dornier, \& Wisniewski, 2016). These phenomena contribute to decreasing the overall hydraulic resistance system and lead therefore to an increase in transmembrane flux.

By comparing the average permeate fluxes calculated between 60 and $120 \mathrm{~min}$ of microfiltration (a steady state is reached in all cases for fouling), the enzymatic hydrolysis made it possible to multiply Jp by 2 to 2.6 (Table 3 ).

Retention and color parameters were also affected by enzymatic liquefaction (Table 3). Retentions of dry matter and betacyanins decreased by a few percent and a few tenths of a percent respectively. The decrease in the retention of the dry matter is probably due to the 
solubilization of part of the insoluble fraction through enzymatic treatment. Betacyanins are located within the vacuoles of plant cells. Enzymatic hydrolysis which contributes to the deconstructing of pecto-cellulosic cell walls, support their release into the juice. After enzymatic treatment, their apparent retention is lower because the amount of betacyanins associated with the insoluble fraction, which is retained by the membrane, decreases. This result is in line with the color measurements: the red coloring $\left(\mathrm{a}^{*}\right)$ of the permeate of the liquefied juice was greater compared to that of the raw juice. The other color parameters $\left(\mathrm{L}^{*}\right.$, $\left.\mathrm{b}^{*}\right)$ did not vary significantly.

The enzymatic treatment of the juice before microfiltration was therefore particularly interesting for our application insofar as it allowed to double the flux of permeate as well as reduce the retention of the desired solutes.

\subsubsection{Effect of transmembrane pressure}

The trend of the curves obtained were quite conventional in MFT (Fig. 3). With the exception of the Pall $0.2 \mu \mathrm{m}$ membrane, the average permeate flux continuously increased with the transmembrane pressure. However, it was not proportional to TMP. In accordance with the generalized Darcy's law, the permeate flux is a function of the ratio of the transmembrane pressure over the permeate's viscosity and the total hydraulic resistance of the system (membrane / fouling). As the resistance of the membrane is constant (incompressible material), this behavior can be explained by an increase of the resistance generated by the fouling when the pressure increases (compressibility of the external fouling on the surface of the membrane, increase of the internal fouling in the porosity of the membrane material).

The best fluxes were obtained with the $0.2 \mu \mathrm{m}$ Tami membrane and exceeded $100 \mathrm{~kg} \mathrm{~h}^{-1} \mathrm{~m}^{-2}$ for a TMP of 2.8 bar. The high flux of permeate obtained under these conditions is interesting for industrial application.

On the other hand, the TMP and the type of membrane do not have a significant impact on the retention of the various compounds present in the juice. Retentions of dry matter and that of betacyanins are very similar. They are on average $9.7 \%$.

From the analysis of these results, in terms of membranes, flux and retentions, it is more interesting to clarify the juice with the $0.2 \mu \mathrm{m}$ Tami membrane at 3 bar TMP using a liquefied feed juice. The selection of these operating conditions makes it possible to obtain a high permeate flux (> $100 \mathrm{~kg} \mathrm{~h}^{-1} \mathrm{~m}^{-2}$ ) and low retentions, in particular for betacyanins. These 
results are interesting in the perspective of a clarification of the juice at an industrial level. In addition, with the membrane sizes used, the permeate obtained is cold sterilized, which ensures a low microbial load in the clarified juice. This microfiltration is well suited as a pretreatment to nanofiltration in order to reduce the fouling properties of the juice by eliminating the insoluble and colloidal parts without significantly modifying the solute composition profile.

The Tami membrane with at 3 bar TMP was therefore logically chosen for clarification with an increasing MRR.

\subsection{Clarification using optimal operating conditions}

Clarification of the liquefied juice was performed up to a MRR of 5.5 with the $0.2 \mu \mathrm{m}$ Tami membrane at 3 bar TMP (Fig. 4). As it is conventionally observed in crossflow microfiltration, the flux gradually decreased according to the MRR. Up to an MRR of 3, the flow droped by $38 \%$ and then gradually stabilized beyond an MRR of 3 . This decrease, in addition to the gradual buildup of the fouling, is attributed to the increase in the viscosity of the juice and its fouling properties. The average permeate flux obtained between 3 and 5.5 of MRR was $83 \mathrm{~kg} \cdot \mathrm{h}^{-1} \cdot \mathrm{m}^{-2}$. The flux remained high even at an MRR of 5, which is not the case during the clarification process of some fruit juices (Fabrice Vaillant, Millan, Dornier, Decloux, \& Reynes, 2001). Considering the high average flux, it would be possible to improve the yield of the clarification by microfiltering the product at MRR greater than 6, without drastic reduction in performance. These results are particularly promising for an industrial scale up of the process.

The main characteristics of the microfiltered juice under these conditions are shown in Table 2. As expected, crossflow microfiltration made it possible to completely clarify the juice, with the turbidity of the permeate reaching less than 1 NTU. The insoluble part contained in the juice was completely eliminated by the process which explained the $9 \%$ retention of TDM. The change in the color of the product, especially $a^{*}$, was probably mainly related to its clarification. With regard to solutes, the composition profile was only slightly modified by the microfiltration. A retention of betacyanins of the order of $4 \%$ was highlighted. This could be explained by the persistence in the liquefied juice of intact cell structures, in which betacyanins would still be present. However, this slight retention does not question the value of the process which makes it possible to clarify and sterilize the juice with good preservation of betacyanins. 


\subsection{Concentration and purification by nanofiltration/ultrafiltration}

\subsubsection{Permeate flux}

During ultra and nanofiltration of juice previously clarified by microfiltration, permeate fluxes only slightly varied over time when TMP was constant (Fig. 5). A slight tendency to decrease was noted but it did not exceed 10\% after 45-50 min of pressure relief. At higher pressures, greater instability was demonstrated for Nadir membranes. It could be related to a greater sensitivity of these membranes to slight pressure fluctuations generated by the feed piston pump.

The average permeate fluxes calculated over the last $10 \mathrm{~min}$ of each pressure stage were used to compare the membranes with each other depending on the TMP. The permeate fluxes obtained during the ultra or nanofiltration tests, with 4 membranes of MWCO between 0.2 and $4 \mathrm{kDa}$, were very sensitive to the increase of the TMP (Fig. 6). From 5 bar, the evolution of average fluxes according to TMP was linear for all membranes $\left(r^{2} \geq 0.99\right)$ with slopes ranging from 1.05 to $2.66 \mathrm{~kg} \cdot \mathrm{h}^{-1} \cdot \mathrm{m}^{-2} \cdot \mathrm{bar}^{-1}$. The sensitivity of the flux to the TMP was 2 times higher on the Nadir $4 \mathrm{kDa}$ membrane, compared to the average sensitivity of the other membranes. This is probably related to its much higher MWCO than the others. Koch membrane $1 \mathrm{kDa}$ is the least sensitive to pressure. The ordinates at the origin of the flux regression lines for Nadir membranes $1 \mathrm{kDa}$ and $4 \mathrm{kDa}$ were positive, 18.8 and $12.7 \mathrm{~kg} \cdot \mathrm{h}^{-1} \cdot \mathrm{m}^{-2}$ respectively; from this we deduced that the average sensitivity of the fluxes according to TMP for these membranes increased considerably at low pressure (TMP $<5$ bar). This behavior is characteristic of ultrafiltration membranes in which convective transfers are predominant. In this case the increase of permeate flux with pressure is limited by the phenomena of concentration polarization along the surface of the membrane and by fouling. Nadir $1 \mathrm{kDa}$ and $4 \mathrm{kDa}$ membranes were more efficient in terms of flux; at 15 bar for example, their average permeate flux were respectively 41 and $54 \mathrm{~kg} \cdot \mathrm{h}^{-1} \cdot \mathrm{m}^{-2}$.

On the other hand, Nadir $0.2 \mathrm{kDa}$ and Koch $1 \mathrm{kDa}$ membranes showed a characteristic behavior of nanofiltration membranes. In nanofiltration, the impact of the pressure on the flux of solvent, i.e. water in our case, could be represented through Eq. 4. Based on the methodology proposed by (Acosta, Vaillant, Pérez, \& Dornier, 2017), the water permeability 
Koch $1 \mathrm{kDa}$ membranes. A reflection coefficient $\sigma$ of 0.54 was obtained for the 2 membranes. In this case, an important part of the transfers through the membrane is probably related to diffusion-solubilization phenomena.

451

$$
J_{w}=L_{w}(T M P-\sigma \Delta \pi)
$$

452 with

$$
\begin{aligned}
& \mathrm{J}_{\mathrm{w}} \text { : Water flux }\left(\mathrm{kg} \mathrm{h}^{-1} \mathrm{~m}^{-2}\right) \\
& \mathrm{L}_{\mathrm{w}} \text { : Water permeability }\left(\mathrm{kg} \mathrm{h}^{-1} \mathrm{~m}^{-2} \mathrm{bar}^{-1}\right)
\end{aligned}
$$

$\sigma:$ Reflexion coefficient

$\Delta \pi$ : Difference of osmotic pressure between both sides of the membrane (bar)
1

2

Among the 4 ultra/nanofiltration membranes tested, the Koch $1 \mathrm{kDa}$ lead to the lowest permeate fluxes $\left(10 \mathrm{~kg} \cdot \mathrm{h}^{-1} \cdot \mathrm{m}^{-2}\right.$ at $\left.15 \mathrm{bar}\right)$. A comparison of the average fluxes obtained with the Nadir $1 \mathrm{kDa}$ and Koch $1 \mathrm{kDa}$ membrane showed that the fluxes were not correlated to the MWCO if the membranes are different. This is probably related to the structural differences in the membranes. If we consider only the Nadir membranes which have a priori a similar structure, we found that the fluxes were positively correlated with MWCO and with the permeability to water.

\subsubsection{Solute retentions}

As it is conventionally observed in nanofiltration, the retention of all solutes increased with TMP and tended asymptotically towards a maximum retention value (Fig. 6). For all membranes, the retention of sugars and citric acid, solutes which are very much in the majority of TDM, was lower (from 0.17 to 0.93 ) than that of betacyanins (from 0.81 to 1.00 ). These differences in retention are most likely related to the difference in molar mass between these two groups of compounds: 180 and $192 \mathrm{~g} \mathrm{~mol}^{-1}$ for sugars and acid and 549 to $550 \mathrm{~g}$ $\mathrm{mol}^{-1}$ for betacyanins.

In all the cases tested, fructose and glucose were retained in the same way regardless of the operating parameters. On the other hand, citric acid was more or less retained depending on the case. Nadir $1 \mathrm{kDa}$ and $4 \mathrm{kDa}$ membranes retained more citric acid than sugars; the retentions were almost equal with the Koch membrane $1 \mathrm{kDa}$; the retention of citric acid was lower than that of sugars with Nadir $0.2 \mathrm{kDa}$ membrane. For the same cutoff of $1 \mathrm{kDa}$, the Koch membrane showed retentions $34 \%$ higher on average than the Nadir membrane. This 
observation is related to the differences in structure and material between the 2 membranes as already mentioned by comparing permeates fluxes.

Betacyanins were better retained than major solutes, probably because of their higher molecular weight but also their overall positive charge. Indeed, the ionization of these compounds probably contributes to increase their retention via repulsive electrostatic forces, the membranes being rather positively charged at such pH (Conidi, Cassano, \& Drioli, 2012). Betacyanins were completely retained by Nadir $0.2 \mathrm{kDa}$ membrane even at low TMP values. At high TMP (> 15 bar), retentions greater than $96 \%$ were obtained with $1 \mathrm{kDa}$ cutoff membranes. In cases where the retention of betacyanins was lower, neobetanin was systematically more retained than isobetanin and betanin. This result is surprising because these 3 compounds have an extremely close molecular structure. This phenomenon could be explained by slight variations in the physicochemical interactions between the pigments and the membranes or with the other solutes present into the product.

Although it may happen that practically all the dry matter was retained, the membranes selected in our study were selectively more permeable to major solutes (TDM) than to betanin and isobetanin, which were in turn less retained than neobetanin. As the retention of each of these solutes varied differently depending on the operating conditions, it was then possible to aspire to different separation objectives:

1- concentration of the extract: We will seek in this case, a high retention of all the solutes present. The retentions of all the solutes must be similar in order not to generate a distortion of the composition profile;

2- Purification of betacyanins: It is about favoring the retention of betacyanins to the detriment of that of the other solutes (sugars, acids) in order to increase the content of pigment compared to TDM;

3- Fractionation of betacyanins: Profiling the differences in retention observed between neobetanin and the other 2 betacyanins to separate them.

Regarding treating an extract rich in betacyanins as part of this study, the retention of betacyanins $R_{\beta_{c}}$ must be high in all cases. For the concentration of the extract, the difference in retention between the dry matter and the betacyanins $\left(\mathrm{R}_{\mathrm{TDM}}-\mathrm{R}_{\beta c}\right)$ and the retention difference between the betacyanins themselves $\left(R_{n \beta n}-R_{(\beta n+i \beta n)}\right)$ must be as small as possible (Eq. 3). On the contrary, for the purification, $\left(\mathrm{R}_{\mathrm{TDM}}-\mathrm{R}_{\beta c}\right)$ has to be maximized. Finally, to split 
the betacyanins between them, it is the difference of retentions between neobetanin and betanin/isobetanin $\left(\mathrm{R}_{\mathrm{n} \beta \mathrm{n}}-\mathrm{R}_{(\beta \mathrm{n}+\mathrm{i} \beta \mathrm{n})}\right)$ that must be sought to be maximized. It is therefore possible to represent the retention results in a $3 \mathrm{D}$ space to determine which operating conditions are more favorable for each of the 3 separation objectives described above (

Fig. 7).

The Fig. 8 shows the location of the different couples membrane/pressure tested in this 3D space. The 4 ultra/nanofiltration membranes chosen have quite different specificities. This is interesting insofar as all separation possibilities are conceivable for concentrating, purifying and / or fractioning betacyanins. The concentration of the extract can be implemented without surprise with the Nadir $0.2 \mathrm{kDa}$ membrane but also with the Koch $1 \mathrm{kDa}$ membrane with high transmembrane pressure. The Nadir $1 \mathrm{kDa}$ and $4 \mathrm{kDa}$ membranes are rather indicated for the simultaneous purification and fractionation of betacyanins, and this all the better as the transmembrane pressure is low. Finally, the Koch $1 \mathrm{kDa}$ membrane has a potential for fractionation of betacyanins by limiting TDM losses when used at low pressure. Permeability fluxes obtained under these conditions are however very low.

Table 4 provides a summary of the optimal nanofiltration conditions depending on the targeted separation objective. The results show that for fractionation, the ideal is to operate at low pressure, while purification would require a little higher pressure.

\subsection{Simulation of betacyanin separation by nanofiltration/ultrafiltration}

The different situations presented in Table 4, were used to make simulations in order to evaluate the potentialities of using various membrane / pressure pairs. The simulation was conducted for MRR between 2 and 10, and diavolume DV up to 10, by calculating the betacyanin concentration factor $\left(\mathrm{CF}_{\beta}\right.$, Eq. 2) and the separation factors (Eq.3) either betacyanins compared to $\mathrm{TDM}\left(\mathrm{SF}_{\beta \mathrm{c} / \mathrm{TDM}}\right.$ which corresponds to a purification factor) or among betacyanins $\left(\mathrm{SF}_{\mathrm{n}} \beta_{\mathrm{n}} /\left(\beta_{\mathrm{n}+i} \beta_{\mathrm{n}}\right)\right.$ which corresponds to a fractionation factor).

\subsubsection{Concentration}

In this case, there is no diafiltration step $(\mathrm{DV}=0)$. The concentration factors obtained at a given MRR are very close for the 3 chosen membrane / TMP pairs. For example, with an MRR of 10 , the membranes Nadir $0.2 \mathrm{kDa}$ at 5 bar, Koch $1 \mathrm{kDa}$ at 15 bar and Nadir $1 \mathrm{kDa}$ at 
25 bar make it possible to obtain $\mathrm{CF}_{\beta c}$ of 9.9, 9.2 and 9.1 respectively. This is normal because these membrane / TMP pairs lead to high retentions all greater than 0.96 .

\subsubsection{Purification}

Fig. 9 shows the potential of the 3 selected membrane / TMP pairs to optimize the production of purified betacyanin extracts by diafiltration. These charts, drawn for MRR and DV up to 10, allow visualizing the range of $\mathrm{CF}_{\beta c}$ et $\mathrm{SF}_{\beta}$ /TDM that can be achieved using a given membrane / TMP pair. These figures also make it possible to evaluate the MRR / DV pairs that must be used to reach various levels of concentration and purification. By way of illustration, with a Nadir $1 \mathrm{kDa}$ membrane at 10 bar, to obtain a $\mathrm{SF}_{\beta \mathrm{c} / \mathrm{TDM}}$ of 600 and a $\mathrm{CF}_{\beta \mathrm{c}}$ of 3 , it would be necessary to work with approximately a DV of 9 and to fix the MRR at 7 . The order of magnitude of the purification factors varies greatly from membrane to membrane. For the 3 selected case studies, we find that the Membrane / TMP combinations make it possible to reach average concentration factors, less than 6 , but with high purification factors. The Nadir $4 \mathrm{kDa} / 10$ bar combination makes it possible to envisage a very thorough purification of betacyanins (purification factor up to 3800). Finally, the combination Koch 1 $\mathrm{kDa} / 5$ bar is very limited in terms of separation whereas Nadir $1 \mathrm{kDa} / 10$ bar is intermediate and allows a good compromise between concentration and purification.

\subsubsection{Betacyanins fractionation}

Fig. 10 presenting the results of the simulation carried out with three membrane / TMP pairs gives us information on the feasibility and efficiency of the fractionation. The Koch $1 \mathrm{kDa} / 5$ bar combination gives slightly higher $\mathrm{SF}_{\mathrm{n}} \beta_{\mathrm{n}} /\left(\beta_{\mathrm{n}+\mathrm{i}} \beta_{\mathrm{n}}\right)$ than Nadir $1 \mathrm{kDa} / 5$ bar, similar concentration factors and much lower purification factors. The Nadir $4 \mathrm{kDa} / 5$ bar combination is limited in terms of fractionation but has good concentration and purification factors. With these membranes, however, it is impossible to achieve a separation factor greater than 3.3. This result has to be improved a priori to consider an industrial application, by looking for other combinations membrane / TMP more appropriate to realize this type of separation. 


\section{Conclusion}

120 Crossflow microfiltration had great potential for remove insoluble and colloidal fractions 121 contained in cactus pear juice. Under the operating conditions tested, this first step made it 122 possible to clarify the product perfectly without substantially affecting its solute profile. In 123 particular, the retention of betacyanins was very limited, less than $10 \%$, as for the total dry matter. The Association with an enzymatic pretreatment of liquefaction was really interesting because it multiplied permeate flux at least by 2 and decreased the retention of betacyanins. The results were very encouraging for further development of the process on an industrial scale. After microfiltration, different ways could be considered for the separation of betacyanin by ultra or nanofiltration. By selecting different membrane/pressure settings and adding a possible diafiltration stage, we have shown that it was possible to promote either the concentration of all the betacyanins, or their purification from total dry matter, or even some fractionation between them. The overall process that integrates all these unit operations is an attractive alternative to produce, at low temperature, concentrated and purified betacyanin extracts from cactus pear juice. It could be easily used to pre-concentrate or modify the solute composition of the extract without thermal damage before final concentration (evaporation under vacuu; osmotic evaporation) or spray drying for example. For final validation and better evaluation of the process from an economic point of view, further trials should be performed now at a larger scale of production.

\section{ACKNOWLEDGMENTS}

The authors wish to thank CIRAD and French-Senegal cooperation for financial support. 
Acosta, O., Vaillant, F., Pérez, A. M., \& Dornier, M. (2014). Potential of ultrafiltration for separation and purification of ellagitannins in blackberry (Rubus adenotrichus Schltdl.) juice. Separation and Purification Technology, 125, 120-125.

Acosta, O., Vaillant, F., Pérez, A. M., \& Dornier, M. (2017). Concentration of polyphenolic compounds in blackberry (Rubus Adenotrichos Schltdl.) juice by nanofiltration. Journal of Food Process Engineering, 40(1).

Alard, D., Wray, V., Grotjahn, L., Reznik, H., \& Strack, D. (1985). Neobetanin: isolation and identification from Beta vulgaris. Phytochemistry, 24(10), 2383-2385.

AOAC, A. A. (1990). Official methods of analysis. Vol. I. 15th ed. AOAC, Arlington, VA.

Azeredo, H. (2009). Betalains: properties, sources, applications, and stability-a review. International Journal of Food Science \& Technology, 44(12), 2365-2376.

Bahçeci, K. S. (2012). Effects of pretreatment and various operating parameters on permeate flux and quality during ultrafiltration of apple juice. International Journal of Food Science \& Technology, 47(2), 315-324.

Ballero, M., Poli, F., Sacchetti, G., \& Loi, M. (2001). Ethnobotanical research in the territory of Fluminimaggiore (south-western Sardinia). Fitoterapia, 72(7), 788-801.

Bhattacharjee, C., Saxena, V., \& Dutta, S. (2017). Fruit juice processing using membrane technology: A review. Innovative Food Science \& Emerging Technologies, 43, 136-153.

Cai, Y., Sun, M., \& Corke, H. (2005). HPLC characterization of betalains from plants in the Amaranthaceae. Journal of Chromatographic Science, 43(9), 454-460.

Calvo, C., \& Salvador, A. (2000). Use of natural colorants in food gels. Influence of composition of gels on their colour and study of their stability during storage. Food Hydrocolloids, 14(5), 439-443.

Cassano, A., Conidi, C., \& Drioli, E. (2010). Physico-chemical parameters of cactus pear (Opuntia ficusindica) juice clarified by microfiltration and ultrafiltration processes. Desalination, 250(3), 1101-1104.

Cassano, A., Conidi, C., Timpone, R., D'avella, M., \& Drioli, E. (2007). A membrane-based process for the clarification and the concentration of the cactus pear juice. Journal of Food Engineering, 80(3), 914-921.

Castellanos-Santiago, E., \& Yahia, E. M. (2008). Identification and quantification of betalains from the fruits of 10 Mexican prickly pear cultivars by high-performance liquid chromatography and electrospray ionization mass spectrometry. Journal of Agricultural and Food Chemistry, 56(14), 5758-5764.

Castellar, M., Obón, J., Alacid, M., \& Fernández-López, J. (2008). Fermentation of Opuntia stricta (Haw.) fruits for betalains concentration. Journal of Agricultural and Food Chemistry, 56(11), 4253-4257.

Castellar, M., Obón, J., \& Fernández-López, J. (2006). The isolation and properties of a concentrated red-purple betacyanin food colourant from Opuntia stricta fruits. Journal of the Science of Food and Agriculture, 86(1), 122-128.

Castellar, R., Obón, J. M., Alacid, M., \& Fernández-López, J. A. (2003). Color properties and stability of betacyanins from Opuntia fruits. Journal of Agricultural and Food Chemistry, 51(9), 27722776.

Cejudo-Bastante, M. J. s., Chaalal, M., Louaileche, H., Parrado, J., \& Heredia, F. J. (2014). Betalain profile, phenolic content, and color characterization of different parts and varieties of Opuntia ficus-indica. Journal of Agricultural and Food Chemistry, 62(33), 8491-8499.

Chauhan, S. P., Sheth, N., Rathod, I., Suhagia, B., \& Maradia, R. B. (2013). Analysis of betalains from fruits of Opuntia species. Phytochemistry Reviews, 12(1), 35-45.

Cissé, M., Vaillant, F., Pallet, D., \& Dornier, M. (2011). Selecting ultrafiltration and nanofiltration membranes to concentrate anthocyanins from roselle extract (Hibiscus sabdariffa L.). Food Research International, 44(9), 2607-2614. 
Conidi, C., Cassano, A., Caiazzo, F., \& Drioli, E. (2017). Separation and purification of phenolic compounds from pomegranate juice by ultrafiltration and nanofiltration membranes. Journal of Food Engineering, 195, 1-13.

Conidi, C., Cassano, A., \& Drioli, E. (2012). Recovery of phenolic compounds from orange press liquor by nanofiltration. Food and Bioproducts Processing, 90(4), 867-874.

Dahdouh, L., Delalonde, M., Ricci, J., Servent, A., Dornier, M., \& Wisniewski, C. (2016). Sizecartography of orange juices foulant particles: Contribution to a better control of fouling during microfiltration. Journal of Membrane Science, 509, 164-172.

Delgado-Vargas, F., Jiménez, A., \& Paredes-López, O. (2000). Natural pigments: carotenoids, anthocyanins, and betalains-characteristics, biosynthesis, processing, and stability. Critical Reviews in Food Science and Nutrition, 40(3), 173-289.

Fernandez-Lopez, J. A., \& Almela, L. (2001). Application of high-performance liquid chromatography to the characterization of the betalain pigments in prickly pear fruits. Journal of Chromatography A, 913(1-2), 415-420.

Gökmen, V., \& Çetinkaya, Ö. (2007). Effect of pretreatment with gelatin and bentonite on permeate flux and fouling layer resistance during apple juice ultrafiltration. Journal of Food Engineering, 80(1), 300-305.

Gonçalves, L. C. P., de Souza Trassi, M. A., Lopes, N. B., Dörr, F. A., dos Santos, M. T., Baader, W. J., Oliveira Jr, V. X., \& Bastos, E. L. (2012). A comparative study of the purification of betanin. Food Chemistry, 131(1), 231-238.

Heinrich, M. (2003). Ethnobotany and natural products: the search for new molecules, new treatments of old diseases or a better understanding of indigenous cultures? Current Topics in Medicinal Chemistry, 3(2), 141-154.

Herbach, K. M., Stintzing, F. C., \& Carle, R. (2006). Betalain stability and degradation-structural and chromatic aspects. Journal of food science, $71(4)$.

Hilou, A., Nacoulma, O., \& Guiguemde, T. (2006). In vivo antimalarial activities of extracts from Amaranthus spinosus L. and Boerhaavia erecta L. in mice. Journal of Ethnopharmacology, 103(2), 236-240.

Kujala, T., Loponen, J., \& Pihlaja, K. (2001). Betalains and phenolics in red beetroot (Beta vulgaris) peel extracts: extraction and characterisation. Zeitschrift für Naturforschung C, 56(5-6), 343348.

Loi, M., Poli, F., Sacchetti, G., Selenu, M., \& Ballero, M. (2004). Ethnopharmacology of ogliastra (villagrande strisaili, sardinia, Italy). Fitoterapia, 75(3-4), 277-295.

Medina, E. D., Rodríguez, E. R., \& Romero, C. D. (2007). Chemical characterization of Opuntia dillenii and Opuntia ficus indica fruits. Food Chemistry, 103(1), 38-45.

Mereddy, R., Chan, A., Fanning, K., Nirmal, N., \& Sultanbawa, Y. (2017). Betalain rich functional extract with reduced salts and nitrate content from red beetroot (Beta vulgaris L.) using membrane separation technology. Food Chemistry, 215, 311-317.

Moßhammer, M. R., Stintzing, F. C., \& Carle, R. (2006). Cactus pear fruits (Opuntia spp.): a review of processing technologies and current uses. Journal of the Professional Association for Cactus Development, 8, 1-25.

Nath, K., Dave, H. K., \& Patel, T. M. (2018). Revisiting the recent applications of nanofiltration in food processing industries: Progress and prognosis. Trends in Food Science \& Technology, 73, 1224.

Neelwarne, B. (2012). Red Beet Biotechnology: Food and Pharmaceutical Applications: Springer Science \& Business Media.

Nemzer, B., Pietrzkowski, Z., Spórna, A., Stalica, P., Thresher, W., Michałowski, T., \& Wybraniec, S. (2011). Betalainic and nutritional profiles of pigment-enriched red beet root (Beta vulgaris L.) dried extracts. Food Chemistry, 127(1), 42-53.

Obón, J., Castellar, M., Alacid, M., \& Fernández-López, J. (2009). Production of a red-purple food colorant from Opuntia stricta fruits by spray drying and its application in food model systems. Journal of Food Engineering, 90(4), 471-479. 
Palmese, M. T., Manganelli, R. E. U., \& Tomei, P. E. (2001). An ethno-pharmacobotanical survey in the Sarrabus district (south-east Sardinia). Fitoterapia, 72(6), 619-643.

Polidori, J., Dhuique-Mayer, C., \& Dornier, M. (2018). Crossflow microfiltration coupled with diafiltration to concentrate and purify carotenoids and flavonoids from citrus juices. Innovative Food Science \& Emerging Technologies, 45, 320-329.

Saénz, C., Tapia, S., Chávez, J., \& Robert, P. (2009). Microencapsulation by spray drying of bioactive compounds from cactus pear (Opuntia ficus-indica). Food Chemistry, 114(2), 616-622.

Sant'Anna, V., Gurak, P. D., Marczak, L. D. F., \& Tessaro, I. C. (2013). Tracking bioactive compounds with colour changes in foods-A review. Dyes and Pigments, 98(3), 601-608.

Sawaya, W., Khatchadourian, H., Safi, W., \& Al-Muhammad, H. (1983). Chemical characterization of prickly pear pulp, Opuntia ficus-indica, and the manufacturing of prickly pear jam. International Journal of Food Science \& Technology, 18(2), 183-193.

Stintzing, F. C., \& Carle, R. (2004). Functional properties of anthocyanins and betalains in plants, food, and in human nutrition. Trends in Food Science \& Technology, 15(1), 19-38.

Teles, F., Stull, J. W., Brown, W. H., \& Whiting, F. M. (1984). Amino and organic acids of the prickly pear cactus (Opuntia ficus indica L.). Journal of the Science of Food and Agriculture, 35(4), 421-425.

Ushikubo, F. Y., Watanabe, A. P., \& Viotto, L. A. (2007). Microfiltration of umbu (Spondias tuberosa Arr. Cam.) juice. Journal of Membrane Science, 288(1-2), 61-66.

Vaillant, F., Millan, A., Dornier, M., Decloux, M., \& Reynes, M. (2001). Strategy for economical optimisation of the clarification of pulpy fruit juices using crossflow microfiltration. Journal of Food Engineering, 48(1), 83-90.

Vaillant, F., Millan, P., Jariel, O., Dornier, M., Decloux, M., \& Reynes, M. (1999). Optimization of enzymatic preparation for passion fruit juice liquefaction by fractionation of fungal enzymes through metal chelate affinity chromatography. Food Biotechnology, 13(1), 33-50.

Vaillant, F., Pérez, A. M., Acosta, O., \& Dornier, M. (2008). Turbidity of pulpy fruit juice: a key factor for predicting cross-flow microfiltration performance. Journal of Membrane Science, 325(1), 404-412.

Vergara, C., Cancino-Madariaga, B., Ramírez-Salvo, A., Sáenz, C., Robert, P., \& Lutz, M. (2015). Clarification of purple cactus pear juice using microfiltration membranes to obtain a solution of betalain pigments. Brazilian Journal of Food Technology, 18(3), 220-230.

Wang, L., Yang, G., Xing, W., \& Xu, N. (2008). Mathematic model of the yield for diafiltration processes. Separation and Purification Technology, 59(2), 206-213.

Wang, X.-L., Zhang, C., \& Ouyang, P. (2002). The possibility of separating saccharides from a $\mathrm{NaCl}$ solution by using nanofiltration in diafiltration mode. Journal of Membrane Science, 204(1-2), 271-281.

Watanabe, A. P., Ushikubo, F. Y., \& Viotto, L. A. (2006). Evaluation of permeate flux in microfiltration of Tamarind (Tamarindus indica L.) juice using polypropylene membrane. Desalination, 200(1-3), 337-338.

Wybraniec, S., Starzak, K., Skopińska, A., Nemzer, B., Pietrzkowski, Z., \& Michałowski, T. (2013). Studies on nonenzymatic oxidation mechanisms in neobetanin, betanin, and decarboxylated betanins. Journal of Agricultural and Food Chemistry, 61(26), 6465-6476.

Wyler, H. (1986). Neobetanin: A new natural plant constituent? Phytochemistry, 25(9), 2238. 


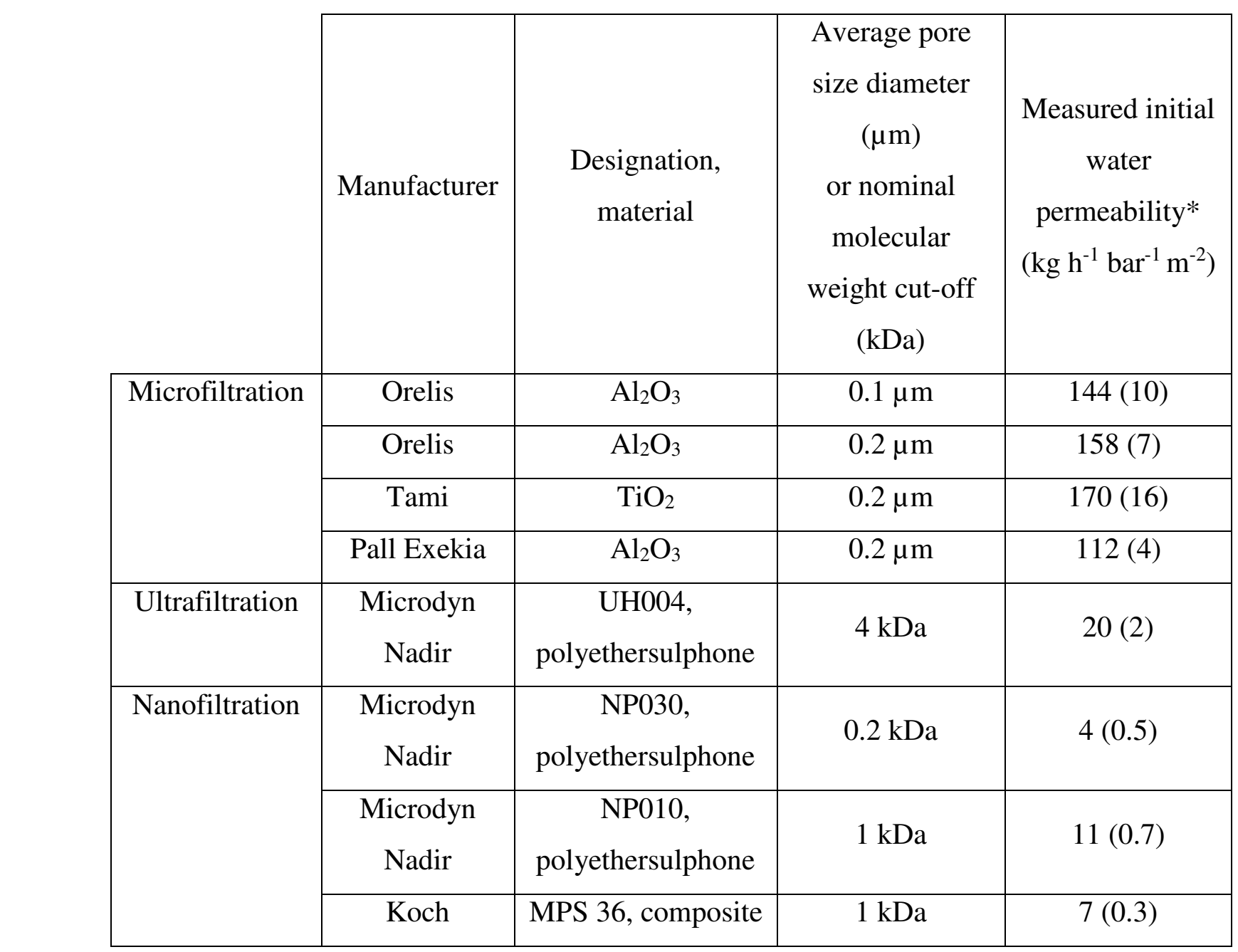


Table 2. Main characteristics of raw cactus pear juice, liquefied juice and microfiltered juice (average and standard deviation evaluated with 3 replicates).

\begin{tabular}{|c|c|c|c|}
\hline Component & Raw juice & $\begin{array}{l}\begin{array}{c}\text { Liquefied } \\
\text { juice }\end{array} \\
\text { Ultrazym }\end{array}$ & $\begin{array}{c}\text { Microfiltered juice } \\
\text { Membrane Tami } 0.2 \mu \mathrm{m} \\
\text { TMP }=3 \text { bar } \\
3.0 \leq \text { MRR } \leq 5.5\end{array}$ \\
\hline $\mathrm{TDM}\left(\mathrm{g} \cdot \mathrm{kg}^{-1}\right)$ & $65.6(0.5)$ & $64.6(0.4)$ & $58.8(0.7)$ \\
\hline TSS $\left(\mathrm{g} \cdot \mathrm{kg}^{-1}\right)$ & $72(1)$ & $72(1)$ & $75(1)$ \\
\hline $\mathrm{pH}$ & $3.35(0.05)$ & $3.32(0.05)$ & $3.38(0.01)$ \\
\hline Citric acid $\left(\mathrm{g} \cdot \mathrm{kg}^{-1}\right)$ & $12.4(0.4)$ & $12.4(0.3)$ & $12.9(0.1)$ \\
\hline Glucose $\left(\mathrm{g} \cdot \mathrm{kg}^{-1}\right)$ & $22.8(0.1)$ & $22.8(0.1)$ & $22.9(0.2)$ \\
\hline Fructose $\left(\mathrm{g} \cdot \mathrm{kg}^{-1}\right)$ & $22.8(0.2)$ & $22.9(0.1)$ & $22.9(0.2)$ \\
\hline Betacyanins $\left(\mathrm{g} \cdot \mathrm{kg}^{-1}\right)$ & $0.76(0.02)$ & $0.77(0.01)$ & $0.74(0.04)$ \\
\hline Turbidity (NTU) & $1428(37)$ & $1430(33)$ & $<1$ \\
\hline Conductivity $\left(\mathrm{mS} . \mathrm{cm}^{-1}\right)$ & $3.72(0.22)$ & $3.74(0.12)$ & $3.53(0.21)$ \\
\hline $\mathrm{L}^{*}$ & $8.89(0.17)$ & $8.87(0.18)$ & $9.68(0.14)$ \\
\hline$a^{*}$ & $16.5(0.4)$ & $16.6(0.5)$ & $33.4(3.0)$ \\
\hline $\mathrm{b}^{*}$ & $-1.8(0.1)$ & $-2.6(0.1)$ & $-0.9(0.2)$ \\
\hline
\end{tabular}


Table 3. Permeate flux (Jp), retentions and color of permeate obtained during microfiltration of raw and liquefied cactus pear juice at MRR $=1$ using different membrane / transmembrane pressure (TMP) combinations.

\begin{tabular}{|c|c|c|c|c|c|c|c|c|}
\hline \multirow{3}{*}{ Membrane/TMP } & \multirow{2}{*}{\multicolumn{2}{|c|}{$\begin{array}{c}\text { Permeate } \\
\text { flux }\left(\mathrm{kg} \cdot \mathrm{h}^{-1} \cdot \mathrm{m}^{-2}\right)\end{array}$}} & \multicolumn{4}{|c|}{ Retentions } & \multirow{2}{*}{\multicolumn{2}{|c|}{$\begin{array}{l}\text { Permeate } \\
\text { colour }\left(\mathrm{a}^{*}\right)\end{array}$}} \\
\hline & & & \multicolumn{2}{|c|}{$\begin{array}{l}\text { Total dry } \\
\text { matter }\end{array}$} & \multicolumn{2}{|c|}{ Betacyanins } & & \\
\hline & $\begin{array}{l}\text { Raw } \\
\text { juice }\end{array}$ & $\begin{array}{l}\text { Liquefied } \\
\text { juice }\end{array}$ & $\begin{array}{l}\text { Raw } \\
\text { juice }\end{array}$ & $\begin{array}{c}\text { Liquefied } \\
\text { juice }\end{array}$ & $\begin{array}{l}\text { Raw } \\
\text { juice }\end{array}$ & $\begin{array}{c}\text { Liquefied } \\
\text { juice }\end{array}$ & $\begin{array}{l}\text { Raw } \\
\text { juice }\end{array}$ & $\begin{array}{l}\text { Liquefied } \\
\text { juice }\end{array}$ \\
\hline Orelis- $0,1 \mu \mathrm{m} / 1.78$ bar & $34.8(1.5)$ & $75.3(3.3)$ & 0.12 & 0.09 & 0.11 & 0.09 & 34.1 & 37.9 \\
\hline Orelis-0,2 $\mu \mathrm{m} / 3.32 \mathrm{bar}$ & $37.1(1.8)$ & $97.0(4.0)$ & 0.10 & 0.10 & 0.16 & 0.08 & 26.0 & 41.7 \\
\hline Pall- $0,2 \mu \mathrm{m} / 2.81$ bar & $34.0(1.6)$ & $75.8(3.6)$ & 0.08 & 0.05 & 0.15 & 0.05 & 23.3 & 37.9 \\
\hline Tami- $0,2 \mu \mathrm{m} / 2.29 \mathrm{bar}$ & $43.3(1.5)$ & $89.5(2.4)$ & 0.10 & 0.09 & 0.13 & 0.09 & 35.7 & 41.6 \\
\hline
\end{tabular}


Table 4. Selection of the optimal operating conditions for concentration, purification and

\begin{tabular}{|c|c|c|c|}
\hline \multirow{2}{*}{ Membrane } & \multicolumn{3}{|c|}{ Transmembrane pressure TMP (bar) } \\
\cline { 2 - 4 } & Concentration & Purification & Fractionation \\
\hline Nadir $0.2 \mathrm{kDa}$ & 5 & - & - \\
\hline Koch $1 \mathrm{kDa}$ & 15 & 5 & 5 \\
\hline Nadir $1 \mathrm{kDa}$ & 25 & 10 & 5 \\
\hline Nadir $4 \mathrm{kDa}$ & - & 10 & 5 \\
\hline
\end{tabular}




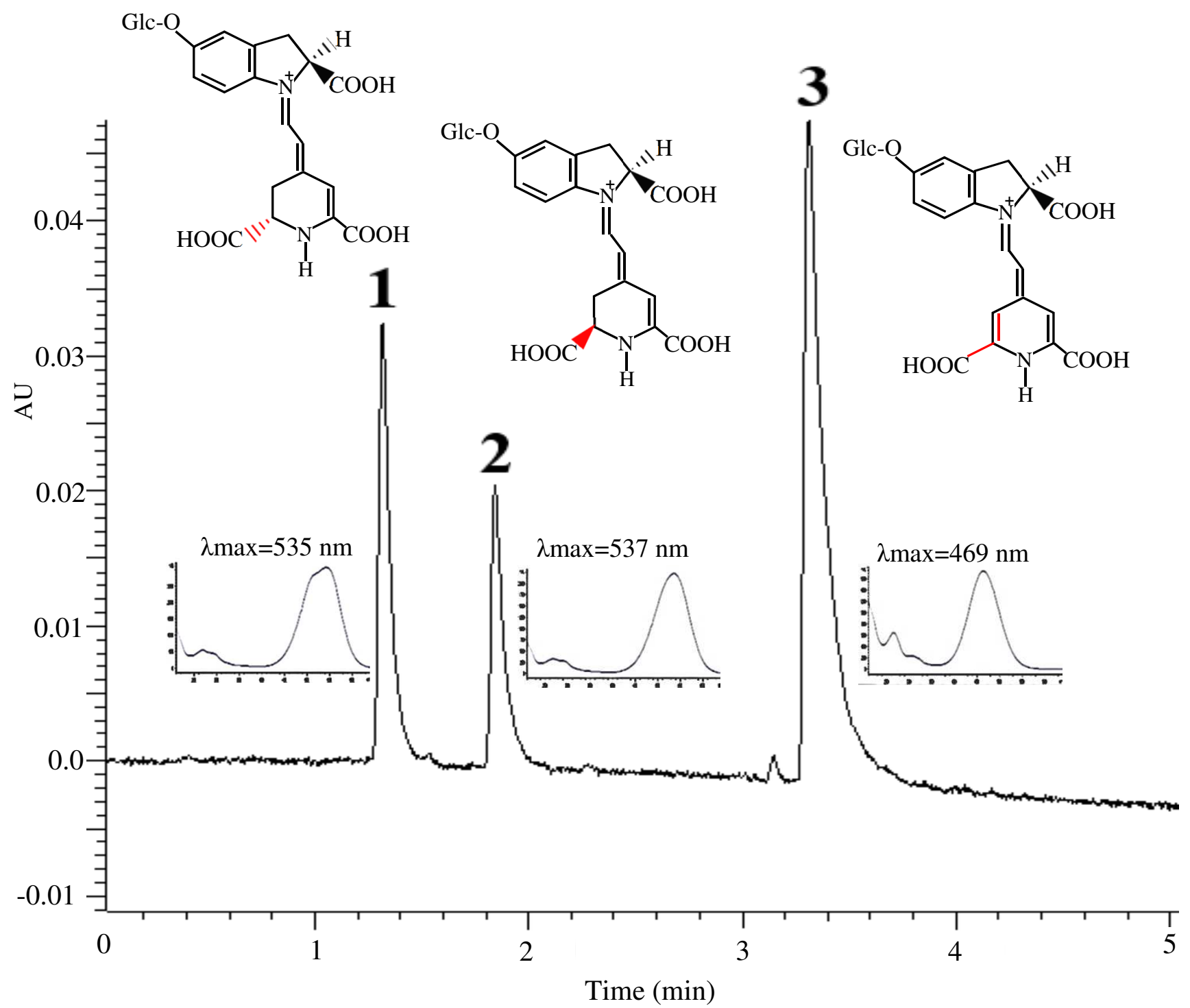

Fig. 1. HPLC chromatograms at $484 \mathrm{~nm}$ of the betacyanins extracted from raw cactus pear juice with their visible absorption spectrum: betanin (1), isobetanin (2), neobetanin (3). 


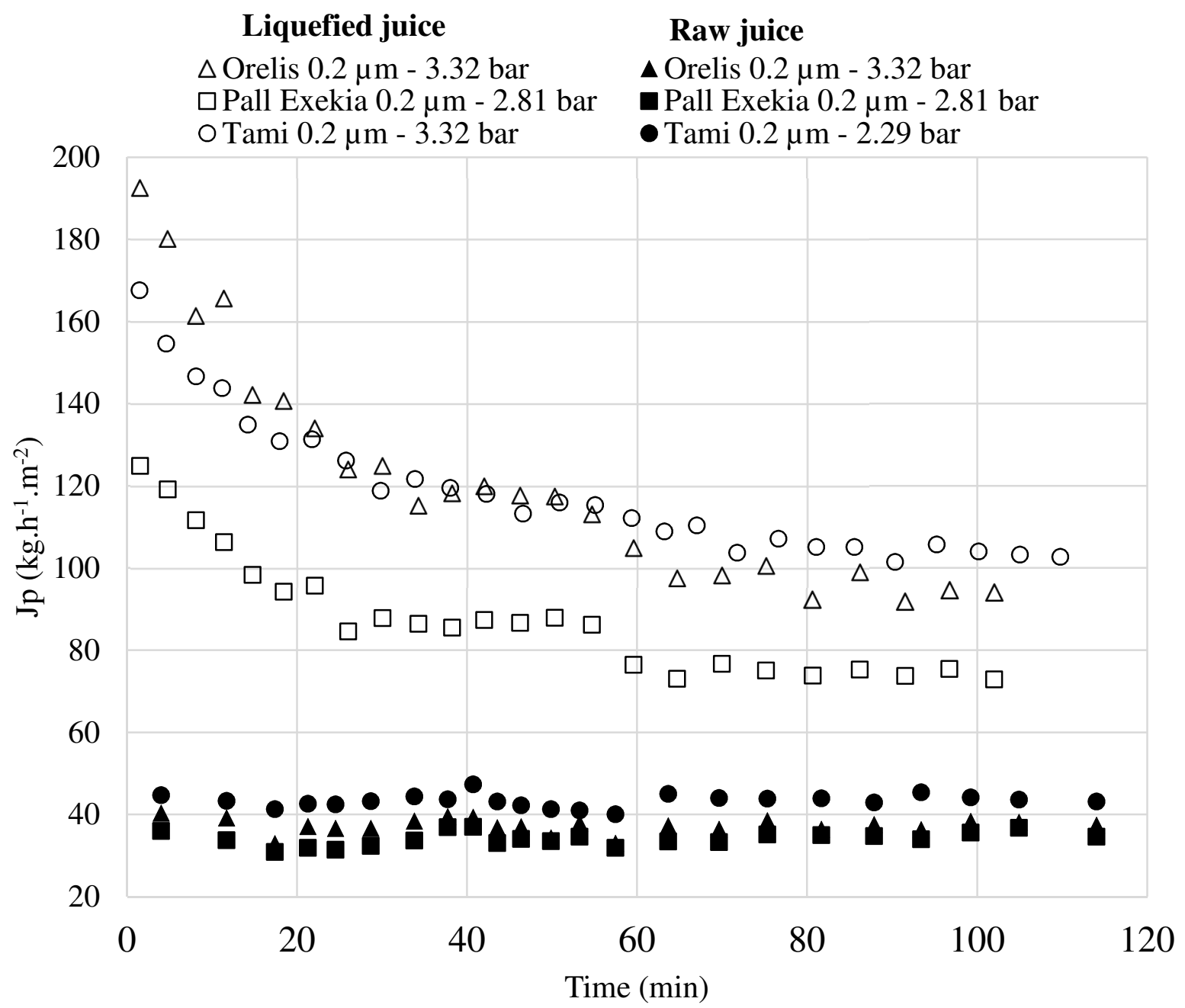

Time (min)

Fig. 2. Examples of permeate flux (Jp) evolution vs. time during the clarification of cactus pear juice by microfiltration at MRR $=1$ with different membranes and operating conditions. 
$\triangle$ Orelis- $0.1 \mu \mathrm{m} \quad \square$ Orelis- $0.2 \mu \mathrm{m} \quad \circ$ Pall- $0.2 \mu \mathrm{m} \quad \times$ Tami- $0.2 \mu \mathrm{m}$

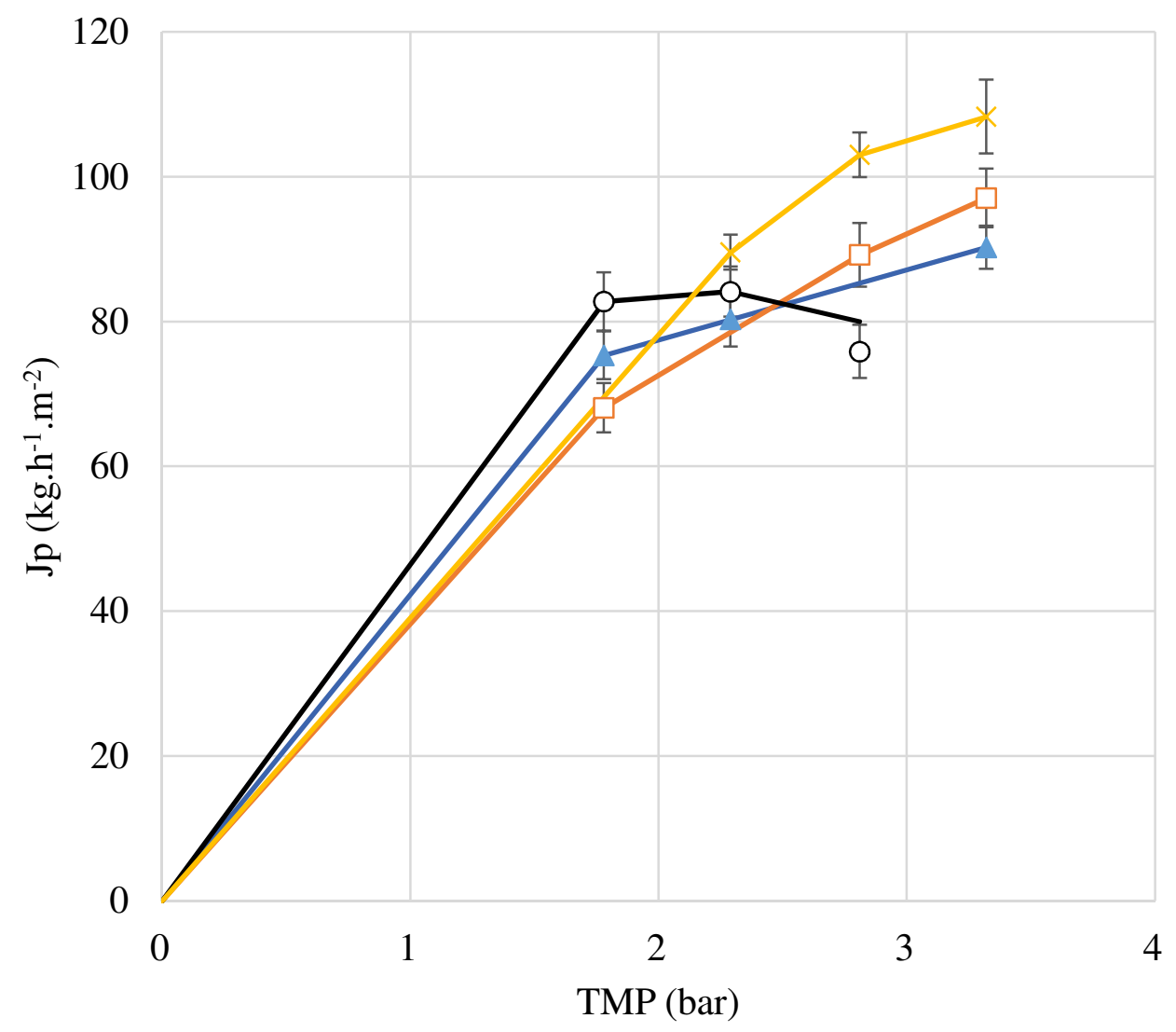

Fig. 3. Effect of transmembrane pressure (TMP) on permeate flux (Jp) during microfiltration of liquefied cactus pear juice using different membranes at MRR $=1$. 


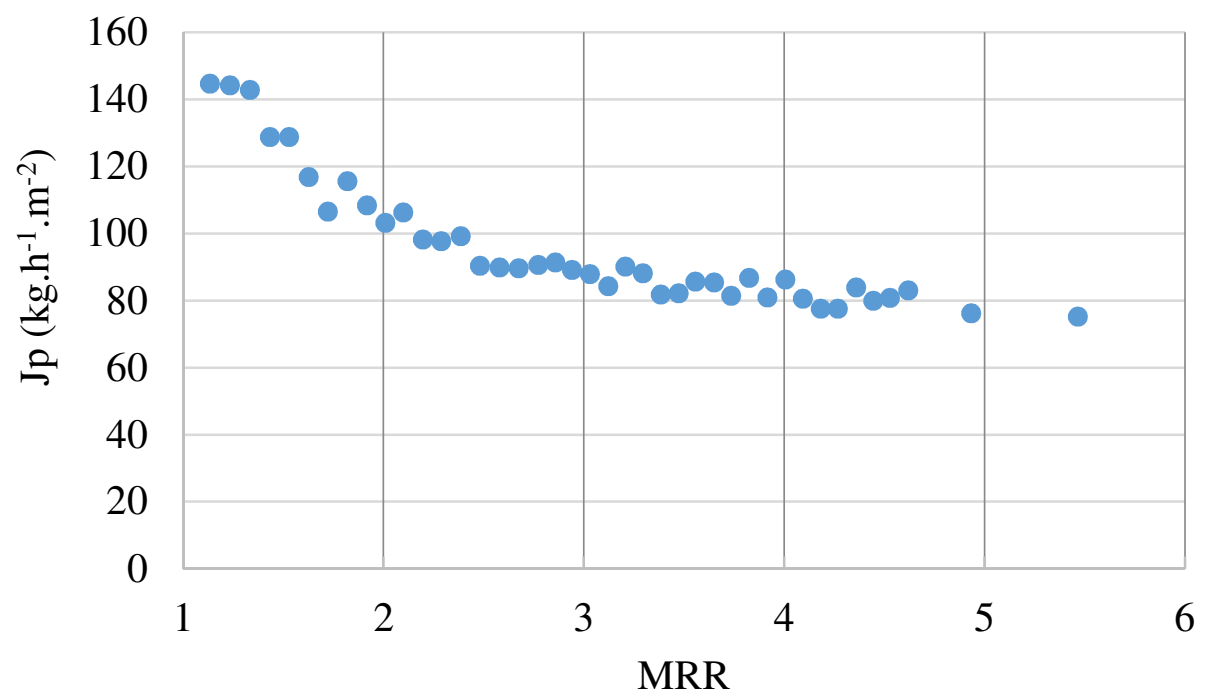

332

333

334 Fig. 4. Permeate flux (Jp) vs. mass reduction ratio (MRR) during the clarification of liquefied 335 cactus pear juice by microfiltration (membrane Tami $0.2 \mu \mathrm{m}, \mathrm{TMP}=3$ bar).

336 


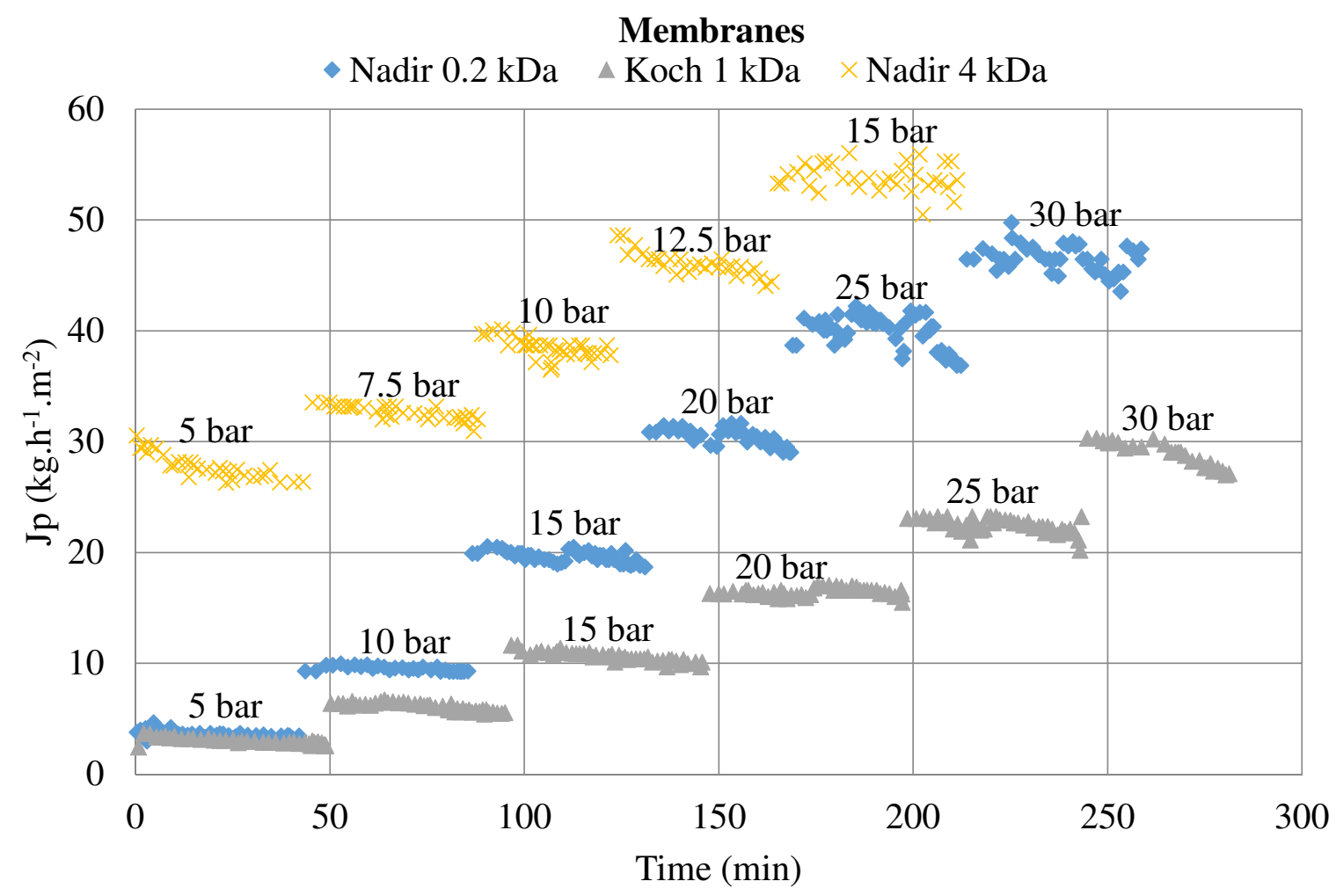

Fig. 5. Examples of the evolution of permeate flux (Jp) vs. time during ultra/nanofiltration of microfiltered cactus pear juice increasing transmembrane pressure. 
$\triangle \mathrm{TDM} \square$ Glucose $*$ Citric acid - Betanin - Isobetanin $\diamond$ neobetanin $\diamond$ Flux
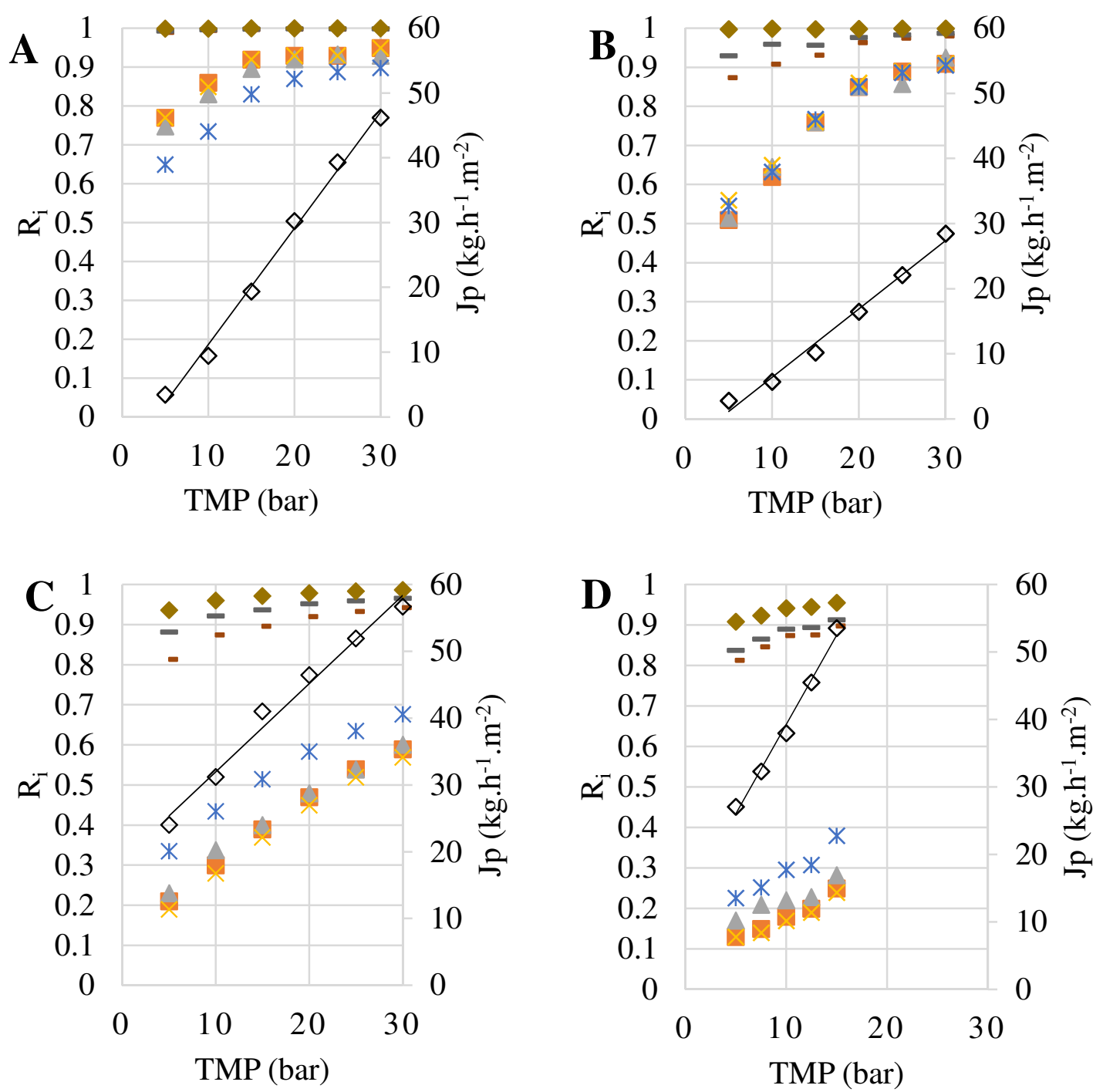

Fig. 6. Permeate flux (Jp) and solute retentions $\left(\mathrm{R}_{\mathrm{i}}\right)$ obtained at different transmembrane pressures (TMP) during ultra/nanofiltration of microfiltered cactus pear juice using the 


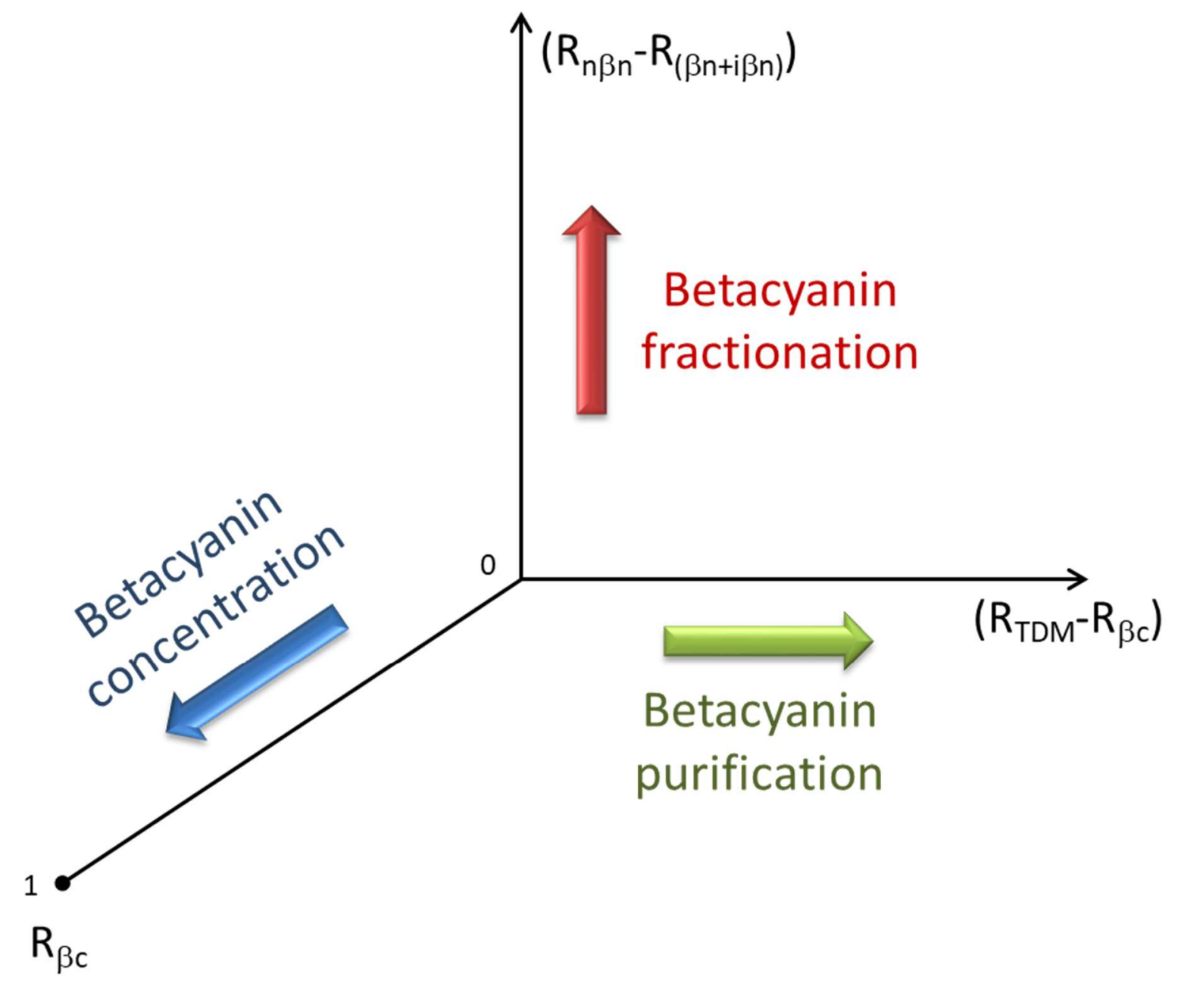

351

Fig. 7. Potential types of separation by nanofiltration that can be considered according to solute retentions $R_{i}$ ( $\beta c$ total betacyanins, $n \beta n$ neobetanin, $(\beta n+i \beta n)$ betanin and isobetanin, TDM total dry matter). 


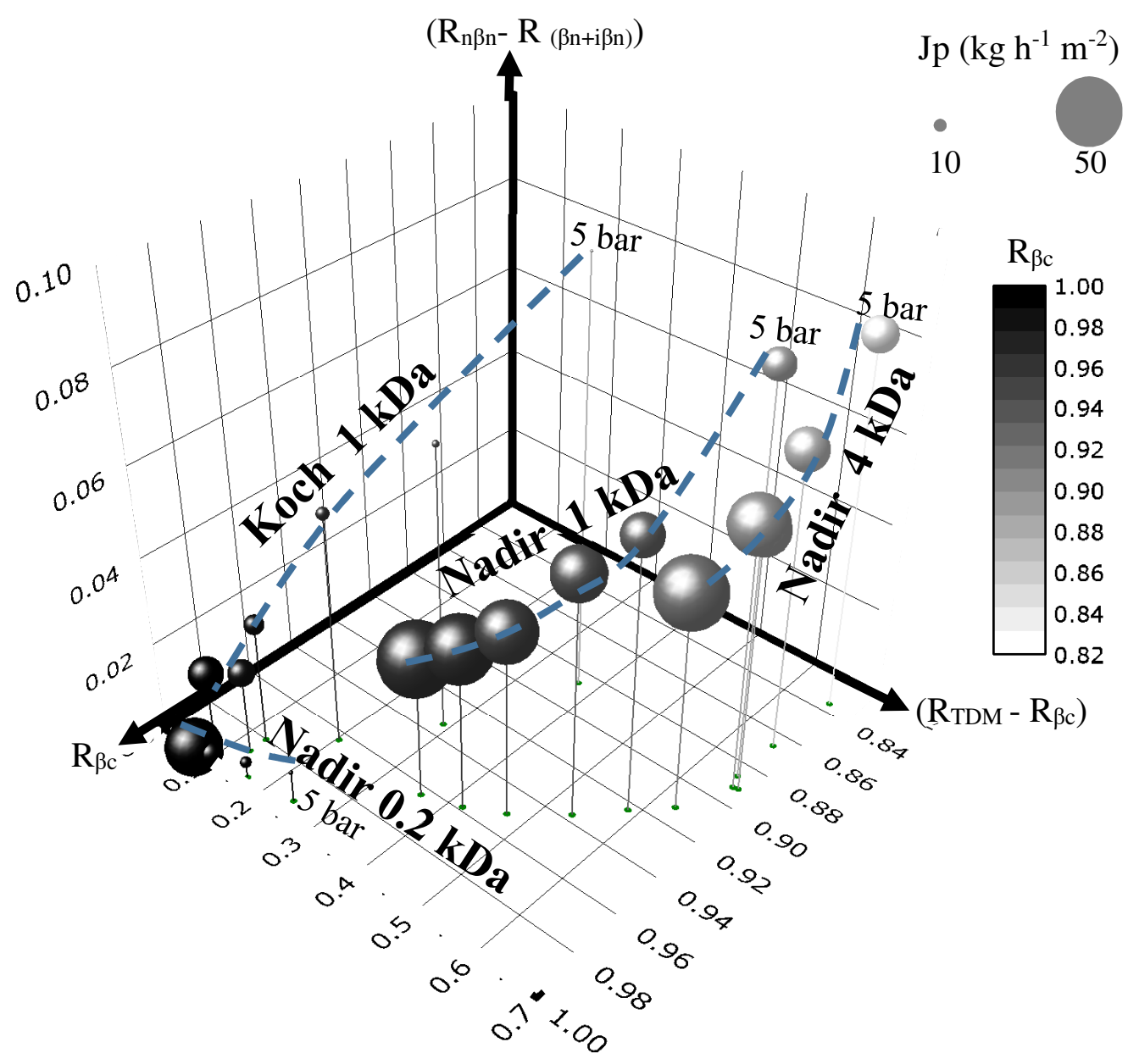

Fig. 8. Representation of the different combinations membrane/pressure tested for ultra/nanofiltration of microfiltered cactus pear juice according to the solute retentions $R_{i}(\beta c$ total betacyanins, $n \beta n$ neobetanin, $(\beta n+i \beta n)$ betanin and isobetanin, TDM total dry matter) and permeate flux obtained $(\mathrm{Jp})$. 

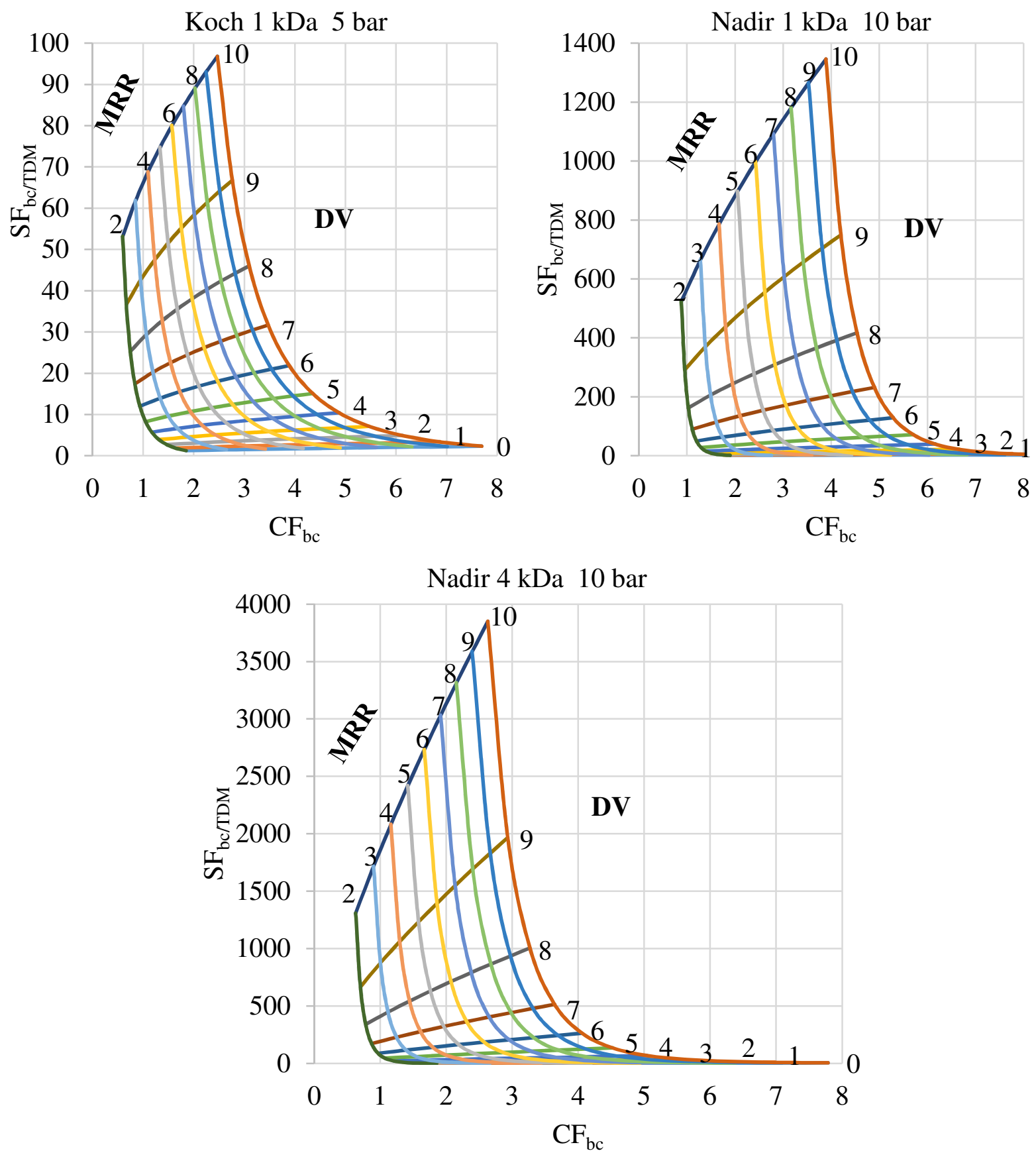

Fig. 9. Concentration factor of betacyanins $\left(\mathrm{CF}_{\beta c}\right)$ and separation factor between betacyanins and total dry matter $\left(\mathrm{SF}_{\beta \mathrm{c} / \mathrm{TDM}}\right)$ achievable in the case of 3 membrane/TMP combinations according to the mass reduction ratio (MRR) and the diavolume (DV) for the purification by ultra/nanofiltration of betacyanins of microfiltered cactus pear juice. 

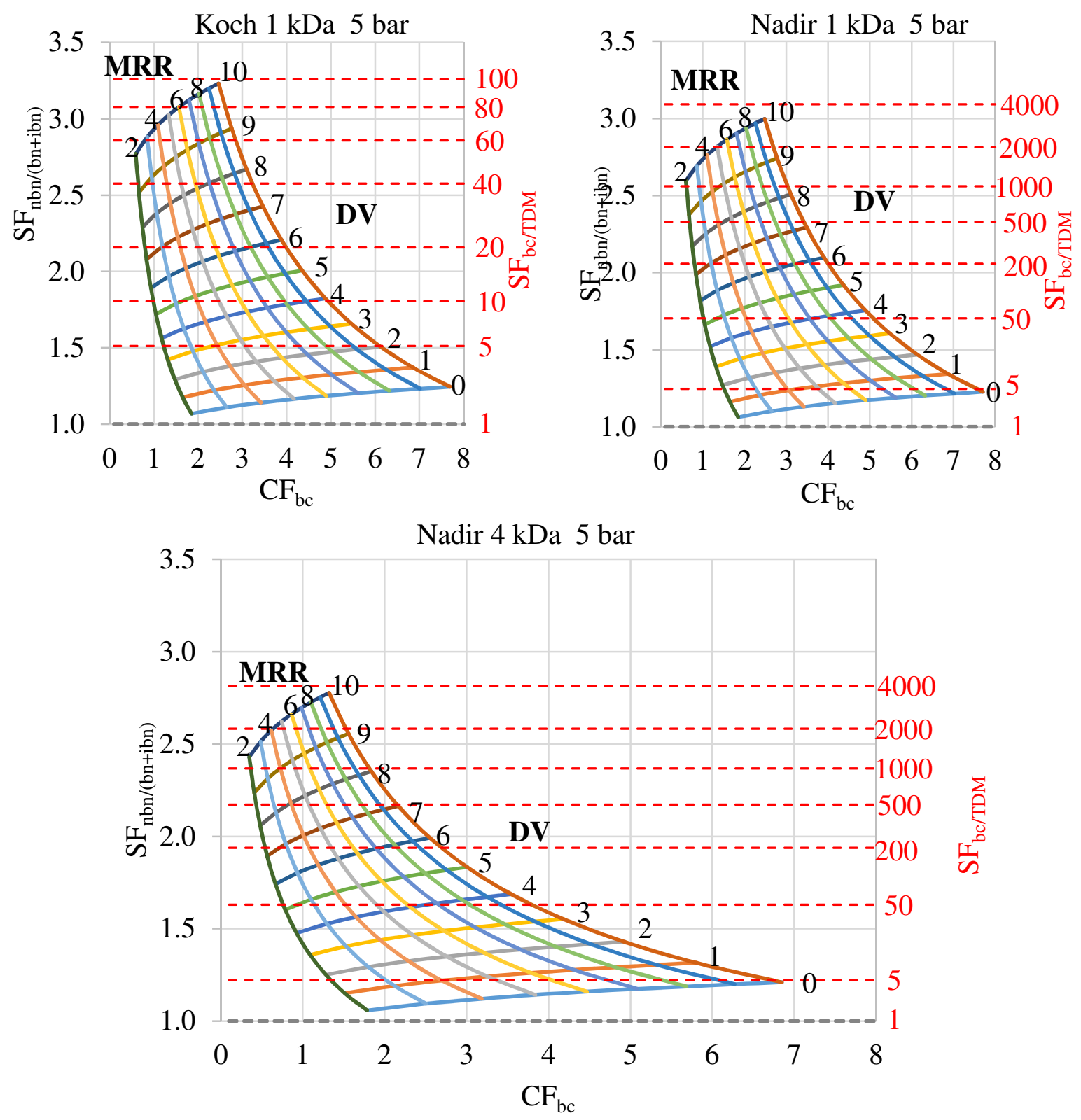

Fig. 10. Concentration factor of betacyanins $\left(\mathrm{CF}_{\beta c}\right)$ and separation factors between betacyanins and achievable in the case of 3 membrane/TMP combinations according to the mass reduction ratio (MRR) and the diavolume (DV) for the fractionation by ultra/nanofiltration of betacyanins of microfiltered cactus pear juice. 